\title{
Convection-Permitting Regional Climate Simulations in the Arabian Gulf Region Using WRF Driven by Bias-Corrected GCM Data
}

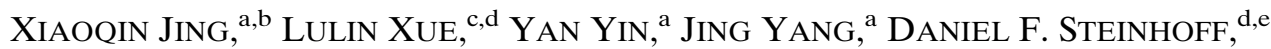 \\ Andrew Monaghan, ${ }^{\mathrm{d}, \mathrm{f}}$ David Yates, ${ }^{\mathrm{d}}$ CHANGHai Liu, ${ }^{\mathrm{d}}$ RoY RASMussen, ${ }^{\mathrm{d}}$ \\ SOURAV TARAPHDAR, ${ }^{\mathrm{g}}$ AND OLIVIER PAULUIS ${ }^{\mathrm{g}, \mathrm{h}}$ \\ ${ }^{a}$ Collaborative Innovation Center on Forecast and Evaluation of Meteorological Disasters, Precision Regional Earth \\ Modeling and Information Center, Nanjing University of Information Science and Technology, Nanjing, China \\ ${ }^{\mathrm{b}}$ Key Laboratory of Cloud and Fog Physical Environment of China Meteorological Administration, Beijing, China \\ ${ }^{\mathrm{c}}$ Hua Xin Chuang Zhi Sci. and Tech. LLC, Beijing, China \\ ${ }^{\mathrm{d}}$ National Center for Atmospheric Research, Boulder, Colorado \\ e Scripps Institution of Oceanography, University of California San Diego, San Diego, California \\ ${ }^{\mathrm{f}}$ University of Colorado, Boulder, Colorado \\ ${ }^{g}$ Center for Prototype Climate Modeling, New York University Abu Dhabi, Abu Dhabi, United Arab Emirates \\ ${ }^{\mathrm{h}}$ Center for Atmosphere Ocean Science, Courant Institute of Mathematical Sciences, New York University, New York,
} New York

(Manuscript received 6 March 2020, in final form 25 June 2020)

\begin{abstract}
The regional climate of the Arabian Gulf region is modeled using a set of simulations based on the Weather Research and Forecasting (WRF) Model, including a 30-yr benchmark simulation driven by reanalysis data, and two bias-corrected Community Earth System Model (CESM)-driven (BCD) WRF simulations for retrospective and future periods that both include 10-yr convection-permitting nested simulations. The modeled precipitation is cross-validated using Tropical Rainfall Measuring Mission data, rain gauge data, and the baseline dataset from the benchmark simulation. The changes in near-surface temperature, precipitation, and ambient conditions are investigated using the BCD WRF simulations. The results show that the BCD WRF simulation well captures the precipitation distribution, the precipitation variability, and the thermodynamic properties. In a warmer climate under the RCP8.5 scenario around the year 2070, the near-surface temperature warms by $\sim 3^{\circ} \mathrm{C}$. Precipitation increases over the Arabian Gulf, and decreases over most of the continental area, particularly over the Zagros Mountains. The wet index decreases while the maximum dry spell increases in most areas of the model domain. The future changes in precipitation are determined by both the thermodynamics and dynamics. The thermodynamic impact, which is controlled by the warming and moistening, results in more precipitation over the ocean but not over the land. The dynamic impact, which is controlled by changes in the large-scale circulation, results in decrease in precipitation over mountains. The simulations presented in this study provide a unique dataset to study the regional climate in the Arabian Gulf region for both retrospective and future climates.
\end{abstract}

\section{Introduction}

In water-scarce regions, such as the Arabian Gulf region, water systems are particularly vulnerable to population growth and economic development (Ouarda et al. 2014). For optimal water resources management, it is necessary to improve our understanding of the precipitation distribution, especially in a changing climate. Many previous studies have indicated a decreasing trend of precipitation amount in the arid and semiarid areas.

\footnotetext{
Corresponding author: Lulin Xue, lulin.xue@gmail.com
}

Using ground-based station measurements, Al-Rashed and Sherif (2000) showed a rainfall and runoff deficit in the United Arab Emirates (UAE) between 1980 and 2000, with consequent persistent drought. Modarres and Sarhadi (2009) showed that the annual rainfall in Iran is decreasing at most stations based on long-term gauge data. Kwarteng et al. (2009) also reported a decreasing trend of rainfall in Oman based on surface measurements.

Previous studies using global and regional climate models indicate an anticipated decrease in rainfall amounts in most arid and semiarid regions of the globe 
(Chenoweth et al. 2011; Hemming et al. 2010); however, there are large uncertainties in current general circulation models (GCMs) in modeling the details of precipitation distribution due to the relatively coarse horizontal grid resolution and poor representation of some physical processes within these models. For example, snowfall and snowpack are underestimated and their features relative to the topography are poorly resolved due to the low spatial resolution in current GCMs (Rasmussen et al. 2011, 2014). Precipitation initiated from convection, such as thunderstorms and mesoscale convective systems, is significantly biased due to the low resolution and the poorly parameterized convection processes in these models (Ban et al. 2014; Jing et al. 2017; Yang et al. 2018).

Recently, numerical weather prediction models with high resolution (grid spacing $<6 \mathrm{~km}$ ) that allow deep convection to develop without using deep convection parameterizations have been used to study the regional climate due to advantages of avoiding error-prone convection parameterizations and the improved depiction of the topography (Rasmussen et al. 2011, 2014; Liu et al. 2017; Jing et al. 2017; Wang et al. 2018). Simulations conducted by such a modeling approach are commonly referred to "convection-permitting" simulations (Prein et al. 2015). Ikeda et al. (2010) showed that the Weather Research and Forecasting (WRF) Model at a grid spacing smaller than $6 \mathrm{~km}$ can well simulate the precipitation distribution over the Colorado mountains, especially in cold seasons; the differences between the model outputs and snow gauge measurements were less than $20 \%$ for $71 \%$ of the stations. Rasmussen et al. $(2011,2014)$ also showed that WRF at a resolution of $4 \mathrm{~km}$ can capture the seasonal precipitation distribution over the Colorado headwaters region very well, with differences of $10 \%-$ $15 \%$ compared to gauge measurements. Jing et al. (2017) cross-validated the convection-permitting WRF simulation in the interior western United States using gauge data, radar data, and gauge-based gridded datasets. Their results showed that WRF well captured the seasonal precipitation, especially in winter. Zittis et al. (2017) showed that the WRF Model at a 1-km resolution driven by reanalysis data resulted in better statistics for the simulation of selected rainfall extremes events over Cyprus. Wang et al. (2018) further confirmed that WRF at a resolution of $4 \mathrm{~km}$ accurately simulates the observed distribution and amount of seasonal precipitation and the mountain snowpack in the western United States. The modeled daily minimum and maximum surface temperatures matched the observation-based gridded data, with spatial correlation coefficients close to 1 . Zhang et al. (2016a,b) and Xue et al. (2020, manuscript submitted to Bull. Atmos. Sci. Technol.) demonstrated that WRF longterm simulations with a grid spacing finer than $3 \mathrm{~km}$ can capture the flow-terrain interactions and subsequently the rainfall distributions over the Hawaiian islands. Relevant to the Arabian Gulf region, Wehbe et al. (2019) simulated an extreme precipitation event over the United Arab Emirates using both standalone WRF and coupled WRFHydro models at a resolution of $1 \mathrm{~km}$. They recorded correlations up to 0.82 with an overall bias of $21 \%$ between the simulated and gauge-based precipitation.

Based on the good performance in simulating orographic precipitation over complex terrain, high-resolution WRF simulations have been used to assess changes in precipitation in a changing climate (Rasmussen et al. 2011, 2014; Liu et al. 2017; Prein et al. 2017; Musselman et al. 2017; Wang et al. 2018; Jing et al. 2019). For instance, using a pseudo-global warming (PGW) approach, Rasmussen et al. $(2011,2014)$ analyzed the hydrological cycle in the Colorado headwaters region using convectionpermitting WRF simulations and explored its sensitivity to climate change. Liu et al. (2017) recently extended the work to the contiguous United States and showed a widespread increase in precipitation in the future scenario. Jing et al. $(2018,2019)$ analyzed the wintertime precipitation distribution over the complex terrain in the interior western United States and showed that climate change results in more significant absolute increases over the mountains than the plains. Xue et al. (2020, manuscript submitted to Bull. Atmos. Sci. Technol.) found that the thermodynamics changes in PGW simulation lead to a lower trade wind inversion in summer, which impacts the spatial rainfall pattern in Hawaii accordingly.

However, previous studies mainly applied the PGW approach, in which the future climate is driven by reanalysis data that are adjusted by the mean climate perturbations from GCM model(s). Therefore, the lowfrequency variability and teleconnection patterns are implicitly assumed to remain unchanged in the future climate in the model, and the potential future changes in the baroclinic systems and their impacts on the precipitation cannot be revealed (Liu et al. 2017; Jing et al. 2019). Some studies tried to dynamically downscale the GCM data with regional climate model (RCM) simulations to address such impacts (e.g., Laprise et al. 2008; Bender et al. 2010; Done et al. 2015). However, GCMs typically have large uncertainties and can cause significantly biased regional climatology. Recently, some bias correction methods were developed to reduce the uncertainties in GCMs, such as correcting bias in the mean and variance (Xu and Yang 2015), quantile-quantile mapping (Colette et al. 2012), and feature location correction (Levy et al. 2013). White and Toumi (2013) tested both the mean bias correction and quantile-quantile mapping methods, and found that the mean bias correction method is more reliable. Bruyère et al. (2014) tested six limited-area 
TABLE 1. Description of WRF Model configurations for all experiments.

\begin{tabular}{|c|c|c|c|c|}
\hline & & Benchmark & $\mathrm{BCD}$ retrospective & $\mathrm{BCD}$ future \\
\hline \multirow[t]{3}{*}{ Simulation periods } & D1 & $1981-2010$ & 1986-2005 & 2060-79 \\
\hline & D2 & $1981-2010$ & 1986-2005 & $2060-79$ \\
\hline & D3 & & 1990-99 & $2065-74$ \\
\hline \multirow[t]{3}{*}{ Resolution and grids } & D1 & \multicolumn{3}{|c|}{$36 \mathrm{~km}, 282 \times 132$ grid points, and 40 vertical levels } \\
\hline & $\mathrm{D} 2$ & \multicolumn{3}{|c|}{$12 \mathrm{~km}, 270 \times 222$ grid points, and 40 vertical levels } \\
\hline & D3 & \multicolumn{3}{|c|}{$4 \mathrm{~km}, 348 \times 327$ grid points, and 40 vertical levels } \\
\hline \multirow[t]{7}{*}{ Physical choices } & Cumulus & \multicolumn{3}{|c|}{ Grell-Devenyi cumulus scheme (not used in D3) } \\
\hline & Microphysics & \multicolumn{3}{|c|}{ Lin bulk cloud microphysics scheme } \\
\hline & PBL & \multicolumn{3}{|c|}{ Yonsei University (YSU) PBL scheme } \\
\hline & Surface layer & \multicolumn{3}{|c|}{ MM5 surface layer scheme } \\
\hline & Land surface & \multicolumn{3}{|c|}{ Noah-MP land surface scheme } \\
\hline & Longwave & \multicolumn{3}{|c|}{ RRTMG longwave radiation scheme } \\
\hline & Shortwave & \multicolumn{3}{|c|}{ Dudhia shortwave radiation scheme } \\
\hline
\end{tabular}

numerical experiments driven by bias-corrected GCM data, each correcting different bias components. They found that correcting all the essential thermodynamics and dynamic variables provides the greatest improvement, and their biascorrected model outputs have been used in later RCM simulations (Zittis et al. 2020). Despite the efforts that have been made to downscale the GCM data with RCMs, very few convection-permitting RCM simulations driven by a bias-corrected GCM have been conducted up to now.

To better understand the future climate changes in the Arabian Gulf region, a high-resolution $(4 \mathrm{~km})$ convectionpermitting WRF-based RCM is deployed, which dynamically downscaled the climate of the Arabian Peninsula region using bias-corrected GCM outputs for lateral boundary conditions in this study. With the bias-corrected GCM data being implemented, not only the thermodynamics impacts but also the changes in baroclinic systems are included. To our knowledge, this is the first study that uses bias-corrected GCM data to conduct convectionpermitting RCM simulations in the Arabian Gulf region. The purpose of this paper is to evaluate the ability of WRF driven by bias-corrected GCM data in modeling the climatology in the Arabian Gulf region, and to investigate the potential changes under the global warming environment.

The paper is organized as follows: section 2 describes the numerical approach and the observational datasets for model verification, section 3 evaluates the retrospective simulation, section 4 presents the future changes predicted by the RCM simulations, a discussion is given in section 5 , and section 6 summarizes the conclusions.

\section{Numerical approach and data description}

\section{a. WRF model setup and numerical experiments}

In this study, a set of WRF-based simulations are designed (Table 1), including a 30-yr (1981-2010) benchmark simulation with two nested domains driven by reanalysis data, and two bias-corrected Community Earth System Model (CESM)-driven (BCD) simulations for retrospective (1986-2005) and future (2060-79) periods. The latter two experiments both include 10-yr (1990-99 and 2065-74) convection-permitting nested simulations (Fig. 1). The mean bias in CESM data was corrected before driving the WRF simulation; the bias correction method is detailed in section $2 \mathrm{~b}$.

For the benchmark simulation, the European Centre for Medium-Range Weather Forecasts interim reanalysis (ERA-Interim, herein ERAI; Simmons et al. 2006; Dee et al. 2011) was used to provide the initial and boundary conditions. ERAI has a spatial resolution of $\sim 0.7^{\circ}$ on 38 vertical levels. Sea surface temperature data are from version 2 of the National Oceanic and Atmospheric Administration Optimum Interpolation $0.25^{\circ}$ product (Reynolds et al. 2007). The outer domain (domain 1) of the benchmark simulations has a resolution of $36 \mathrm{~km}$, and the nested domain 2 has a resolution of $12 \mathrm{~km}$ (Table 1 ). The benchmark simulation, which reasonably represents the real meteorological events and has been confirmed to perform well in modeling the regional climate (e.g., Liu et al. 2017; Wang et al. 2018), provides a baseline dataset to evaluate the BCD WRF simulations.

For the BCD WRF simulations, the two outer domains (D1 and D2) are the same as the benchmark simulations. The innermost domain (D3) has a grid spacing of $4 \mathrm{~km}$ (Table 1), which generates convectionpermitting simulation results. The CESM simulations were performed in support of phase 5 of the Coupled Model Intercomparison Experiment (CMIP5; Taylor et al. 2012) and the Fifth Assessment Report of the Intergovernmental on Climate Change (IPCC 2013), it ranks at the top of all GCMs in its ability to simulate observed temperature and rainfall globally 

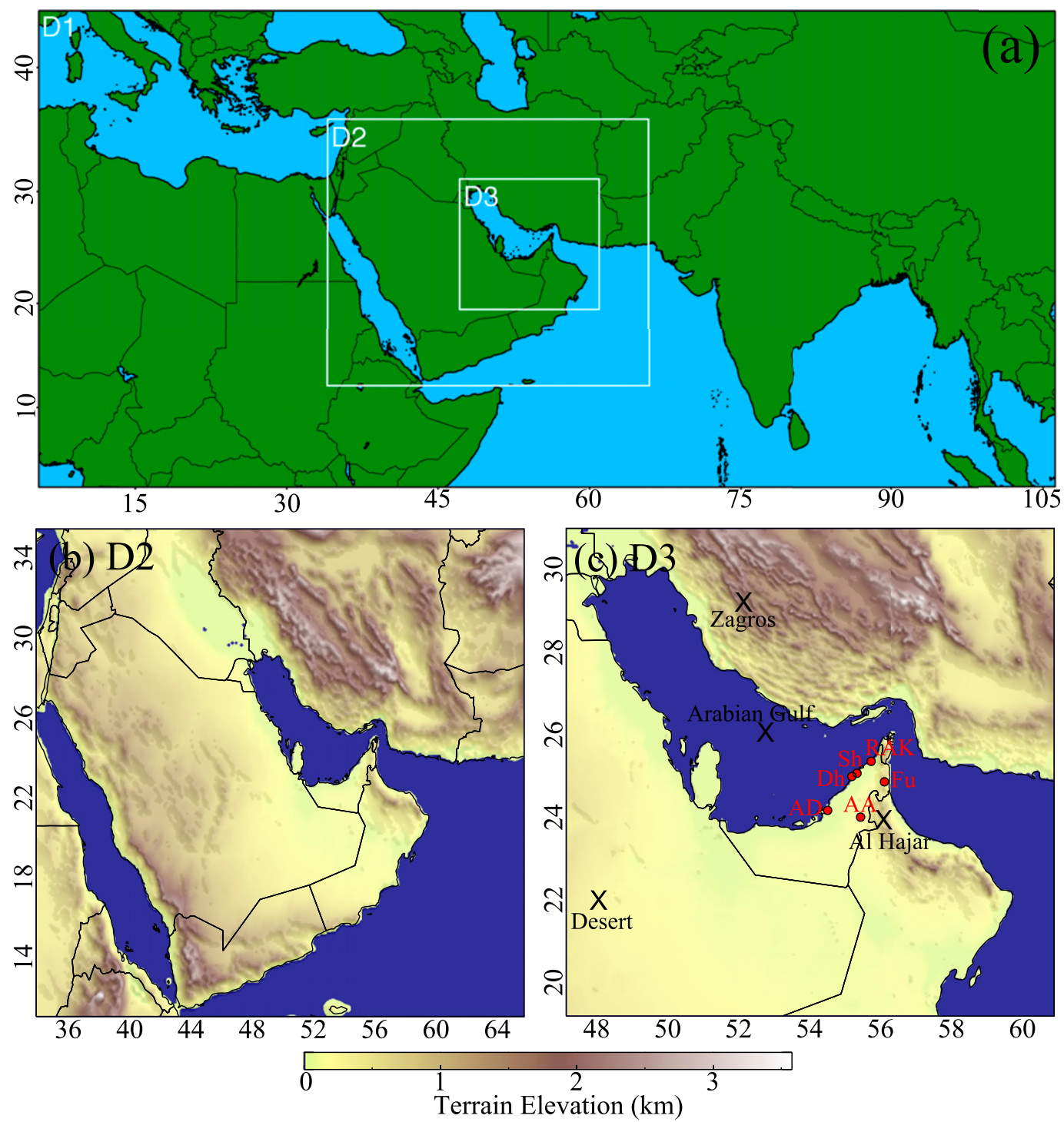

FIG. 1. (a) Domains of the WRF simulations. (b) Map of terrain elevation for domain 2. (c) Map of terrain elevation for domain 3. The red dots in (c) indicate the locations of rain gauges at six major airports in UAE, including Al Ain (AA), Abu Dhabi (AD), Dhabi (Dh), Fujairah (Fu), Ras Al Khaimah (RAK), and Sharjah (Sh). Four different grid points (crosses) are selected for further analysis.

(Knutti and Sedláček 2013). The spatial resolution of $\mathrm{CESM}$ is $0.9^{\circ}$ latitude $\times 1.25^{\circ}$ longitude. For the retrospective simulation, CESM was forced by the observed natural and anthropogenic atmospheric composition changes spanning 1861-2005. Since CESM cannot represent the real meteorological events, the BCD WRF climatology will be evaluated using observational datasets and the benchmark simulation outputs in a statistical manner. For the future projection, the representative concentration pathway (RCP; Moss et al. 2010) 8.5 scenarios, which spans $2006-2100$, is chosen. RCP8.5 is a high-emissions "business as usual" scenario
(Riahi et al. 2011). Although the RCP8.5 conditions are unlikely to happen by the end of this century (Hausfather and Peters 2020), we selected this scenario and the 2060-79 period mostly because the climate change signals, such as temperature and precipitation, would be larger than the systematic biases of the GCMdriven simulations (shown later). This feature provides us the confidence to investigate the future climate changes revealed by the BCD WRF retrospective and future simulations.

In all simulations, the key physics choices are listed in Table 1 . Sensitivity tests suggest these parameterizations 
yielded optimal WRF performance in the Arabian Gulf region (not shown). All the simulations are reinitialized every eight days, and each 8-day period is preceded by a $12-\mathrm{h}$ period that allows the WRF hydrological fields to spin up, which is subsequently excluded. Nudging is not applied in these simulations. The cumulus scheme is used only for D1 and D2 in the model and is switched off in D3 (i.e., the convectionpermitting simulations). It should be clarified that the 4-km grid spacing capably resolves convective storms, but it is insufficient to resolve individual convective elements, especially shallow cumulus clouds. According to previous studies, the $4-\mathrm{km}$ grid spacing is often regarded as a "threshold" to determine whether to use a cumulus scheme, since such simulations allow most convective precipitating events to develop without cumulus parameterization. A comparison of the simulations with different resolutions (e.g., Ikeda et al. 2010; Jing et al. 2017) indicated that models at $4 \mathrm{~km}$ can well simulate the precipitation amount and spatial distribution, and the improvement by further increasing the resolution is insignificant. The nonprecipitating cumulus and the updrafts and downdrafts in deep convection are still at subgrid scales and cannot be explicitly represented by $4-\mathrm{km}$ grid spacing. However, cumulus parameterizations suitable for convectionpermitting models with about $4-\mathrm{km}$ grid spacing are not readily available yet, and existing scale-aware convection schemes in WRF often show little benefit (Tripathi and Dominguez 2013). As a result, as far as we are aware, most convection-permitting RCM simulations with grid spacing of a few kilometers did not use any cumulus parameterizations.

\section{b. Bias correction of GCM data}

Like all GCMs, CESM contains regional-scale biases due to coarse spatial resolution and limited representations of some physical processes. Such biases can adversely affect the dynamical downscaling results and lead to large uncertainty. To remedy these biases, the CESM outputs were adjusted with a recently developed bias correction method (Bruyère et al. 2014) that uses global atmospheric and surface reanalysis to correct the mean bias in the CESM three-dimensional dynamic and thermodynamic variables, and surface and ground states. The technique of bias correction is detailed in Bruyère et al. (2015). The corrected variables are listed in the appendix (Table A1). This method corrects the mean state while retaining synoptic-scale and climate-scale variability simulated by CESM. The reanalysis used for the bias correction is ERAI, which is considered one of the most accurate atmospheric reanalysis datasets available now (e.g., Lorenz and Kunstmann 2012). The bias-corrected CESM dataset is produced by combining a 25-yr (19812005) mean annual cycle from ERAI and a 6-hourly perturbation term from CESM, as follows:

$$
\begin{aligned}
\mathrm{ERAI} & =\overline{\mathrm{ERAI}}+\mathrm{ERAI}^{\prime}, \\
\mathrm{CESM} & =\overline{\mathrm{CESM}}+\mathrm{CESM}^{\prime}, \\
\mathrm{CESM}_{R} & =\overline{\mathrm{ERAI}}+\mathrm{CESM}^{\prime},
\end{aligned}
$$

where terms with overbars are the monthly varying climate averaged over 25 years, terms with primes are the 6-hourly perturbations, and $\mathrm{CESM}_{R}$ is the revised (biascorrected) CESM dataset at 6-hourly intervals. The $\mathrm{CESM}_{R}$ dataset, which can be used as the initial and boundary conditions for RCM simulations, combines a base, monthly varying climate provided by ERAI with daily weather events and climate variability provided by CESM. Using this bias-correction technique, 6-hourly boundary conditions were generated, and the BCD WRF simulations were conducted for both the retrospective and future climates. The bias-corrected CESM dataset is available at NCAR Research Data Archive (Monaghan et al. 2014).

\section{c. Observational datasets}

In this study, the precipitation from the BCD WRF retrospective simulation is evaluated using the Tropical Rainfall Measuring Mission (TRMM) 3B42 precipitation estimate product (Huffman et al. 2007). The TRMM 3B42 dataset provides 3-hourly precipitation at a grid resolution of $0.25^{\circ} \times 0.25^{\circ}$. The precipitation is retrieved using multisatellite data, and is calibrated using the TRMM profiling $\mathrm{Ku}$-band radar and Microwave Imager data. The resolution of the TRMM 3B42 dataset is lower than the resolution of the inner two WRF domains in this study. The retrieved precipitation contain many uncertainties; for example, TRMM cannot capture every precipitation events and it may underestimate the contribution from light precipitation (Iguchi et al. 2000; Schumacher and Houze 2000; Nesbitt and Zipser 2003), and the precipitation may have large bias if the assumed gamma function in the retrieval algorithm cannot represent the true rain drop size distribution. Nevertheless, many previous studies have used the TRMM 3B42 dataset to study precipitation (Schumacher and Houze 2003; Liu et al. 2017), and the TRMM 3B42 data are currently the best long-term observational precipitation estimate for evaluating the modeled distribution and seasonal variability of precipitation in the Arabian Gulf region (Wehbe et al. 2018). 

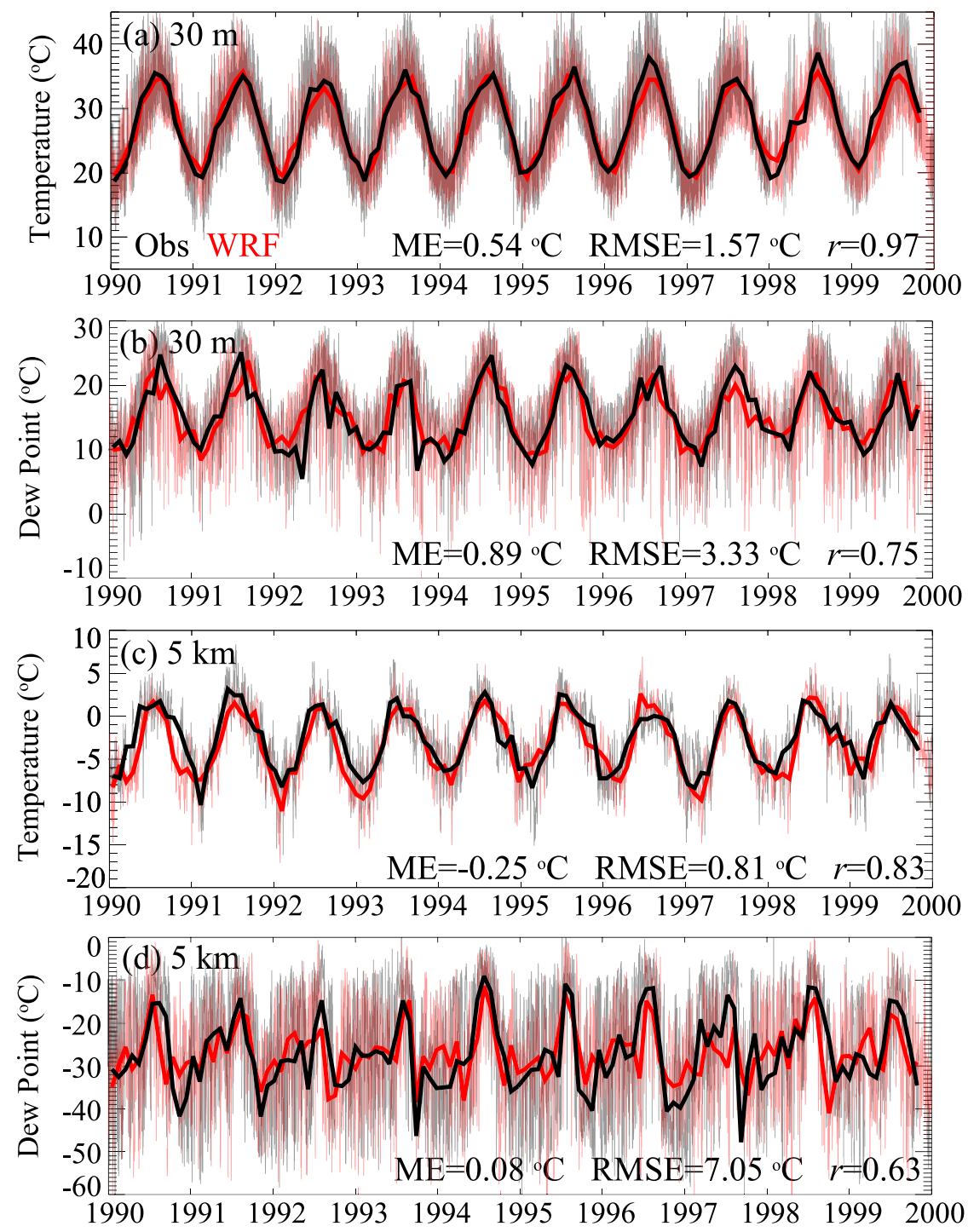

FIG. 2. Time series of temperature and dewpoint temperature at $30 \mathrm{~m}$ and $5 \mathrm{~km}$ above sea level at Abu Dhabi Airport obtained from sounding measurements (black) and BCD WRF simulation (red). The thin lines represent for the 12-hourly data, and the thick lines indicate the monthly means. The mean error (ME), root-mean-square-error (RMSE), and correlation coeffect $(r)$ of the monthly means are labeled in each panel.

In addition, rain gauge datasets from six major airports are used to evaluate the daily precipitation from the bias-corrected CESM-driven retrospective simulation (see Fig. 1c for the names and locations of these sites). Although the rain gauge datasets are available only for six stations, they reflect some spatial variabilities and provide ground truth for the precipitation validation because of its higher accuracy than satellite retrievals (Liu et al. 2017), particularly in the case of the Arabian Gulf region (Wehbe et al. 2017). Sounding data at Abu Dhabi Airport are also used here to evaluate the modeled mean temperature and dewpoint temperature profiles. This validation provides the basis for assessing climate change impacts on thermodynamics.

\section{Verification of the bias-corrected CESM-driven WRF simulation}

\section{a. Temperature and dewpoint temperature}

The BCD WRF-modeled temperature and dewpoint temperature at $30 \mathrm{~m}$ and $5 \mathrm{~km}$ above mean sea level from 1990 to 1999 are evaluated using the sounding measurements at Abu Dhabi Airport (Fig. 2). The 30-m 

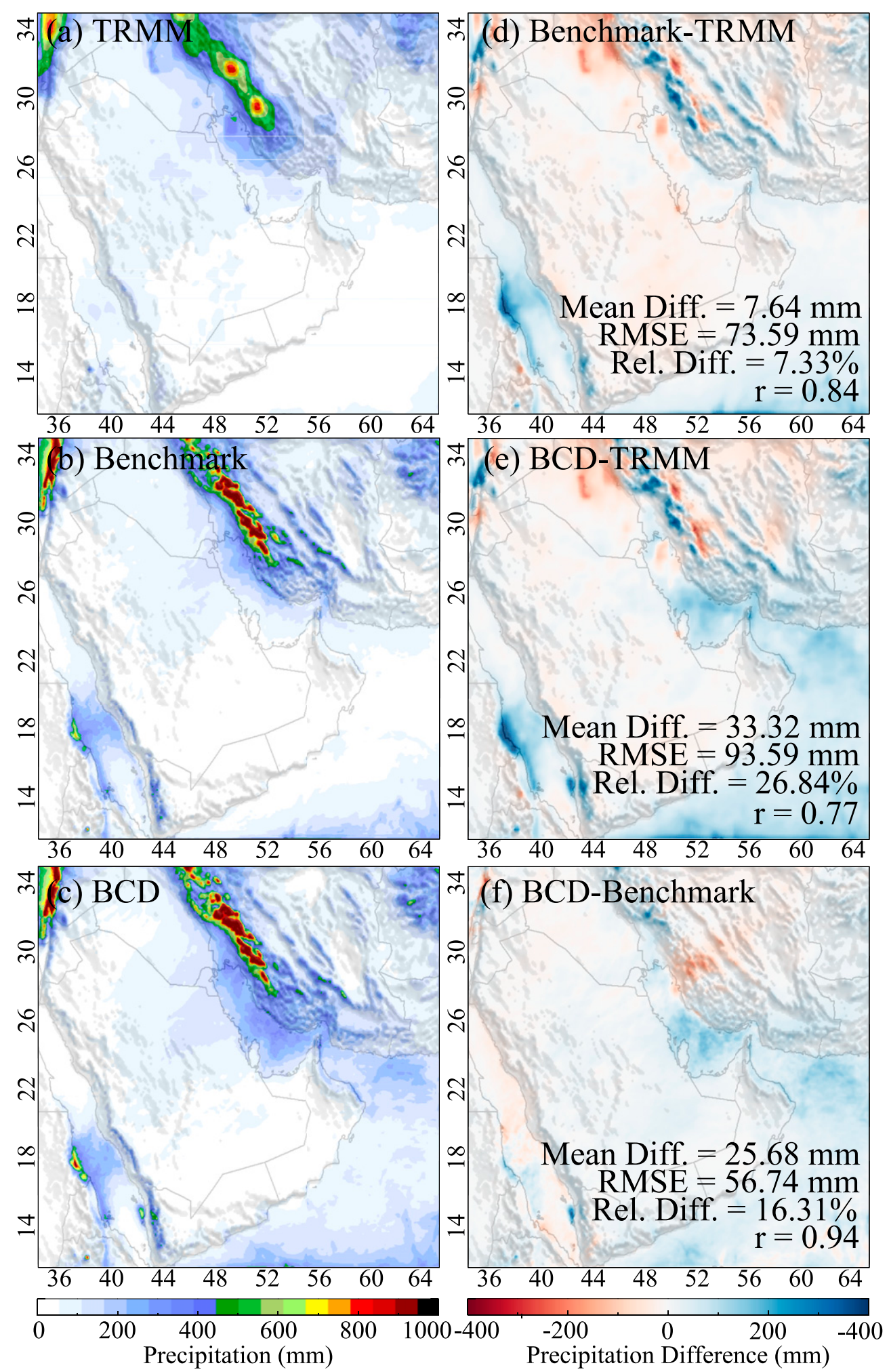

FIG. 3. Wet season (November-April) precipitation in domain 2 estimated by (a) TRMM, (b) the benchmark WRF simulation, and (c) the BCD WRF simulation, as well as their differences, including (d) benchmark - TRMM, (e) BCD - TRMM, and (f) BCD - benchmark. The mean difference, RMSE, relative difference, and spatial correlation coefficient are shown in (d)-(f). 

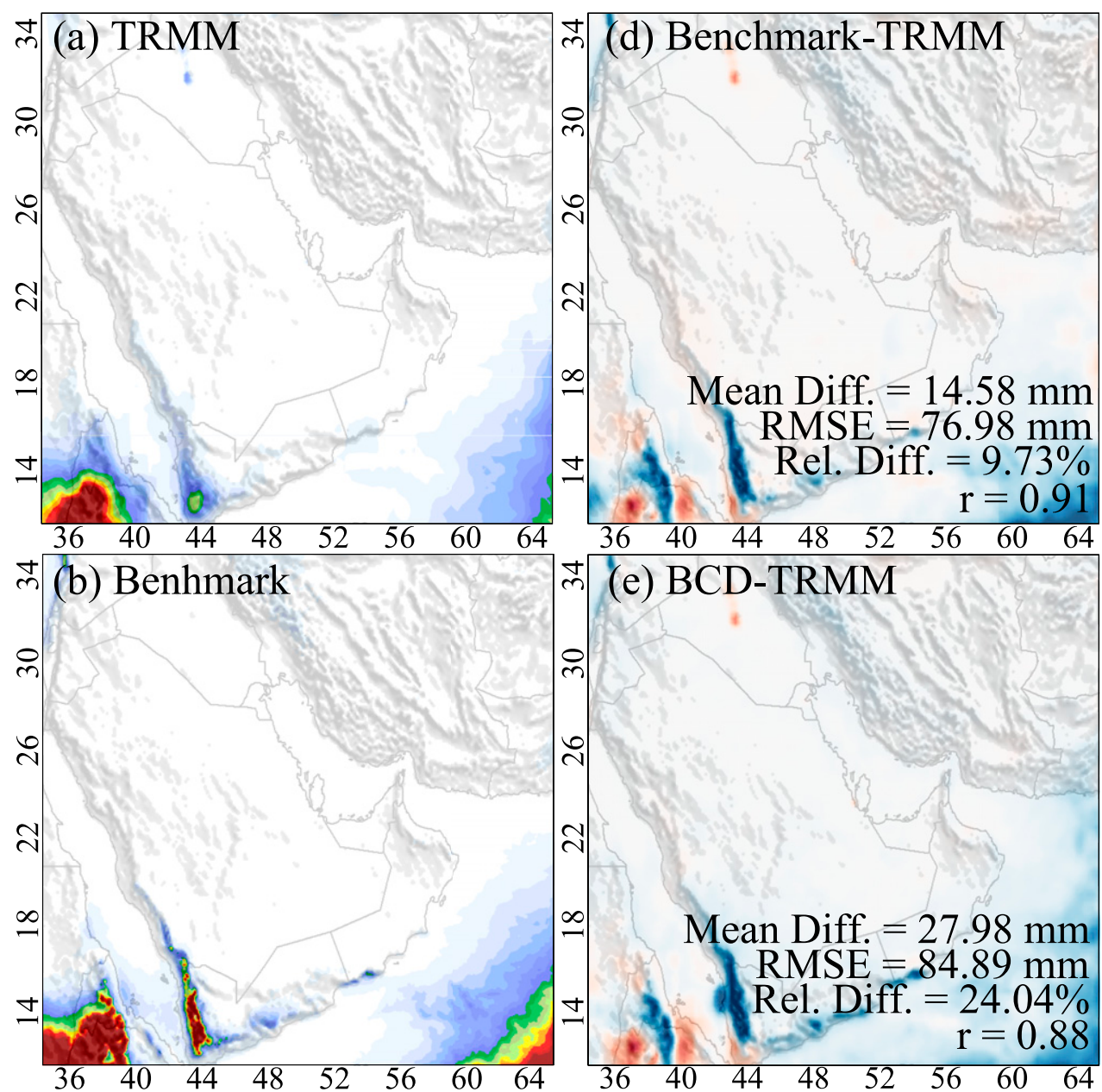

i) (e) BCD-TRMM
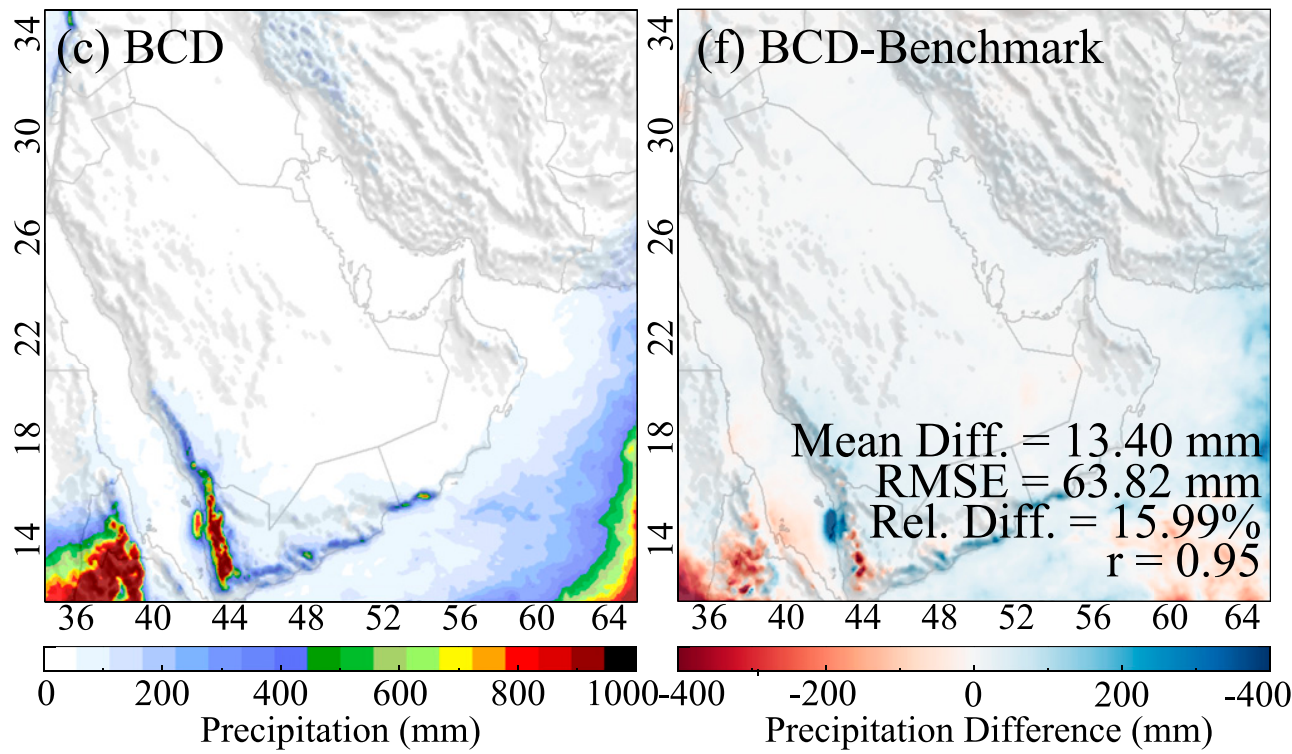

FIG. 4. As in Fig. 3, but for the dry season (May-October) precipitation. 
height is chosen because the lowest level of the sounding measurement is $\sim 30 \mathrm{~m}$. We also plotted the same time series for other levels, and the results are similar. The benchmark simulation is consistent with the observation (not shown to better visualize the observation and BCD WRF simulation). In general, BCD WRF well captures the characteristics of the temperature and dewpoint temperature after bias correction. The seasonal dependence and magnitudes of temperature can be well modeled at both low and high levels. The dewpoint temperature is also season-dependent but more variable than the temperature, especially at higher levels. The modeled dewpoint temperature has larger root-meansquare errors and lower correlation coefficients than the temperature, probably because the large-scale circulations are different in the BCD WRF model and the real world, and the dewpoint temperature is more sensitive to weather events than the temperature. The biases vary for different years because a 25-yr mean annual cycle from ERAI is used in the correction of the CESM data. In addition, the corrected CESM data only provide the boundary conditions for domain 1, so the model uncertainties in domain 1 may cause biases in the nested domains 2 and 3. At both levels, we see the positive biases of the dewpoint temperature (Figs. 2b,d). Actually, the overestimated dewpoint is found in most areas of the study domain by comparing the benchmark simulation and the BCD WRF simulation (not shown). This could result in overestimated precipitation in the Arabian Gulf region by the BCD WRF (shown later in section $3 b)$.

\section{b. Seasonal precipitation}

The seasonal precipitation is cross-validated in this section. Figures 3 and 4 show the precipitation distributions in the wet season (November-April) and dry season (May-October), respectively, in the Arabian Gulf region estimated by TRMM, the benchmark, and the BCD WRF simulations (domain 2), as well as their differences. Since the TRMM data are not available until 1998, and the WRF simulations at 12-km resolution was run from 1986 to 2005, we use the data from 1998 to 2005 in both observations and model results for this figure. In general, the precipitation distributions are consistent among TRMM, the benchmark, and the BCD WRF simulations. The mountainous areas typically receive more precipitation than plain areas. In wet seasons (Figs. 3a-c), more precipitation is observed over the Zagros Mountains in the northern Arabian Gulf region due to the prevailing westerly wind (shown later in Fig. 17), whereas in dry seasons (Figs. 4a-c) more precipitation is found in the southern area, which is related to the local manifestation of the seasonally modulated intertropical convergence zone and the prevailing northerly wind.

The WRF simulations show a finer texture of terrainrelative precipitation distribution than TRMM because of their higher resolution, which results in pronounced differences between TRMM and WRF over mountain areas (Figs. 3d,e and 4d,e). In addition, the WRF simulations and TRMM have slight differences in precipitation over plain areas and the sea, which is probably due to the uncertainties in both the WRF simulations and the satellite retrieval. For instance, WRF at $12-\mathrm{km}$ resolution cannot resolve shallow and moderate convection, and TRMM cannot properly detect precipitation weaker than $\sim 0.5 \mathrm{~mm} \mathrm{~h}^{-1}$ (Nesbitt and Zipser 2003). The distributions of precipitation difference between the benchmark simulation and TRMM (Figs. 3d and 4d) are similar compared to that between BCD simulation and TRMM (Figs. 3e and 4e). On average, the precipitation difference between the benchmark and TRMM is small. The BCD WRF simulation estimates higher precipitation magnitude than TRMM on average.

To further evaluate the BCD WRF-modeled precipitation climatology, we compare the benchmark WRF simulation against the BCD WRF simulation (Figs. $3 \mathrm{f}$ and $4 \mathrm{f}$ ). Although only the model outputs in domain 2 (at a resolution of $12 \mathrm{~km}$ ) are plotted, the comparison is useful to indicate the capability of the BCD WRF simulation in modeling the precipitation climatology of the Arabian Gulf region, because the only difference between the benchmark simulation and BCD WRF simulation is the lateral boundary conditions. A good consistency between the two simulations in domain 3 can be expected if they match well in domain 2. As shown in Figs. 3b,c and 4b,c, the precipitation distributions are similar in these two simulations. In the wet season, the BCD WRF simulation slightly overestimates the precipitation, mainly over the ocean (Fig. 3f), whereas in the dry season the difference mainly occurs at latitudes lower than $18^{\circ} \mathrm{N}$ (Fig. 4f).

The 12-km resolution in domain 2 is coarse compared to typical convection-permitting simulations, so the modeled precipitation may be underestimated such as that over small mountain ranges and that initiated from convection. This can be confirmed in Figs. 5b and 5e, which show finer texture of the terrain-relative precipitation distributions from domain 3. Since domain 3 runs through 1999, only the outputs from 1998 to 1999 are used here. Due to the low spatial resolution and a detecting threshold at $17 \mathrm{dBZ}$ (Iguchi et al. 2000; Schumacher and Houze 2000), the overall precipitation may be underestimated by TRMM (Figs. 5a,d). In addition, TRMM only observes the same place about twice a day, which leads to more uncertainties in the 

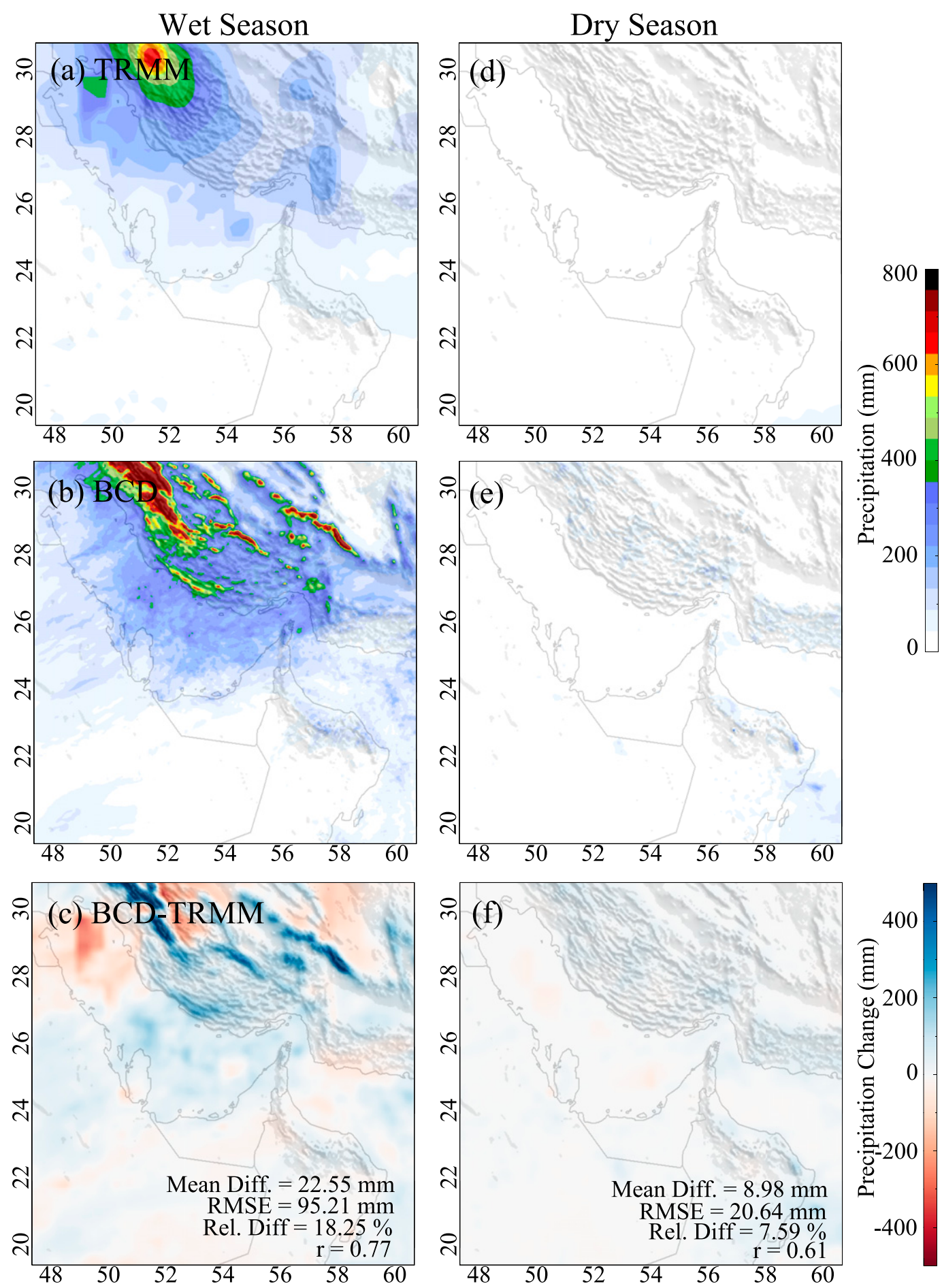

FIG. 5. Wet season (November-April) precipitation in domain 3 estimated by (a) TRMM and (b) the BCD WRF simulation, and (c) their differences. (d)-(f) As in (a)-(c), but for the dry season (May-October).

products, suggesting the fine-resolution model results may be better than TRMM data. Figure 5c shows clear dependence of WRF moist thermodynamic performance on the orography. Structured errors are clearly distinguished between the Gulf itself and the circulation-facing and lee sides of the mountain. In short, the differences in precipitation shown in Figs. $3-5$ are a composite result of the different spatial 

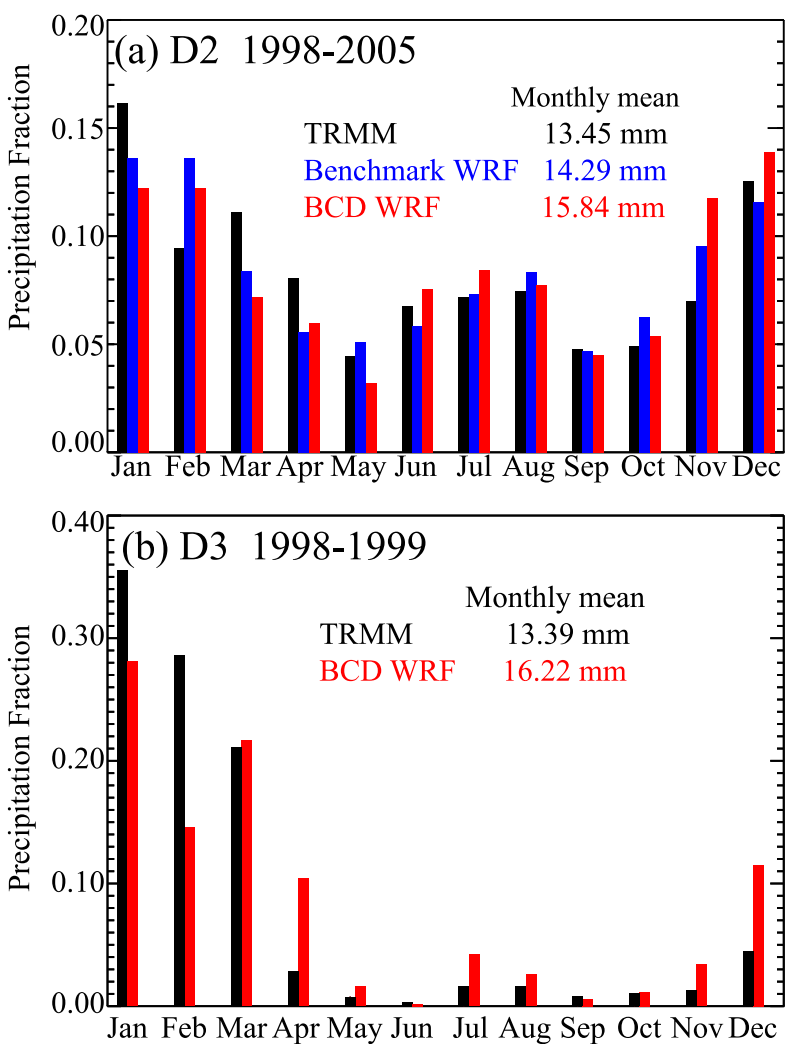

FIG. 6. (a) Monthly precipitation fraction in domain 2 from 1998 to 2005 estimated by TRMM (black), the benchmark WRF (blue), and the BCD WRF (red). (b) As in (a), but for the precipitation from 1998 to 1999 in domain 3 estimated by TRMM and the BCD WRF.

resolutions between TRMM and WRF, the uncertainties of WRF Model and TRMM retrieval, and the sampling limitations of TRMM.

Taking into account the uncertainties of TRMM precipitation, the BCD WRF not only captures the precipitation spatial distributions, but also reasonably captures the characteristics of monthly variability, as shown by the precipitation fraction in Fig. 6, which is calculated using the monthly precipitation divided by the annual precipitation. In Fig. $6 \mathrm{a}$, the modeled precipitation is obtained from the WRF outputs in domain 2, and data from 1998 to 2005 are used, while in Fig. 6b the modeled precipitation is from the BCD WRF outputs in domain 3, and only the data from 1998 to 1999 are analyzed. Although the spatial resolution is higher in domain 3, the modeled precipitation in domain 2 (Fig. 6a) is more consistent with TRMM compared to that in domain 3 (Fig. 6b). A possible reason is that the resolutions are more comparable between TRMM and WRF domain 2. Another reason is that the sample size is smaller for domain 3, so the result may be significantly influenced by individual

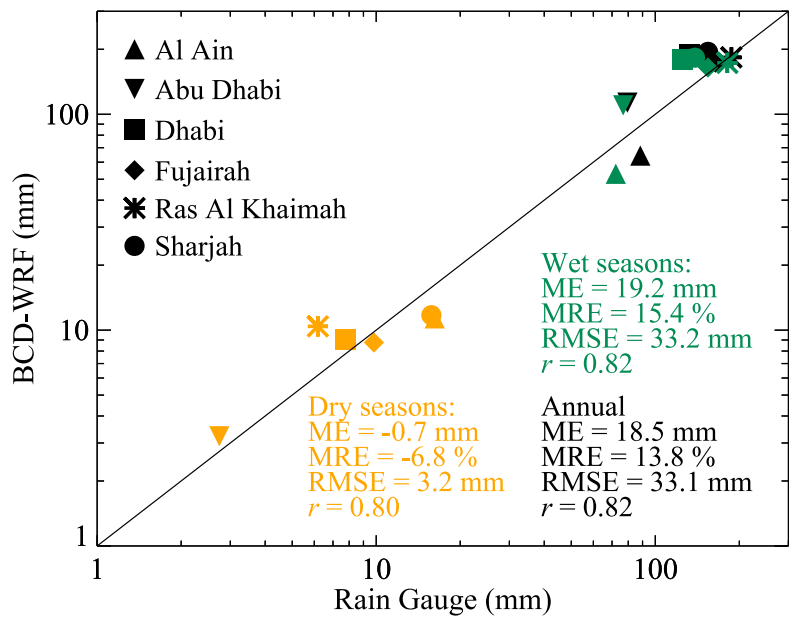

FIG. 7. Scatterplot of dry season, wet season, and annual precipitation from 1990 to 1999 estimated by rain gauge and BCD WRF simulation. The black line is the 1:1 line. The ME, mean relative error (MRE), RMSE, and correlation coefficients of dry season (May-October), wet season (November-April), and annual precipitation between the rain gauge and the BCD WRF simulation are shown.

precipitation events since the BCD WRF simulation is driven by CESM data, in which the weather events are different from the real ones. This inconsistency would be even larger if plotting the monthly precipitation for each year respectively (not shown).

TRMM is useful to evaluate the distributions of precipitation in the Arabian Gulf region, but the accuracy is not as good as surface observations. Therefore, the daily precipitation data measured by the rain gauges at six major airports in UAE are analyzed here to evaluate the precipitation from the convection-permitting $\mathrm{BCD}$ WRF simulation (domain 3). Among the six stations, the rain gauge measurements at $\mathrm{Al}$ Ain International Airport are only available since May 1994. For the other five gauges, the measurements are available from 1990 to 1999 covering the BCD retrospective period. In the model, the grid points closest to each surface station are chosen; we also tried the 9-point distance weighted averages and the results are nearly the same. As shown in Fig. 7, the modeled and observed dry season, wet season, and annual precipitation are consistent. WRF tends to slightly underestimate the dry season precipitation, and to overestimate the wet season and annual precipitation. The correlation coefficients between the modeled and observed precipitation are equal to or higher than 0.8. Again, because the large-scale circulation and weather events are different between the BCD WRF simulation and the real ones, day-to-day and month-to-month comparisons would result in significant inconsistency between the modeled and observe precipitation (not 

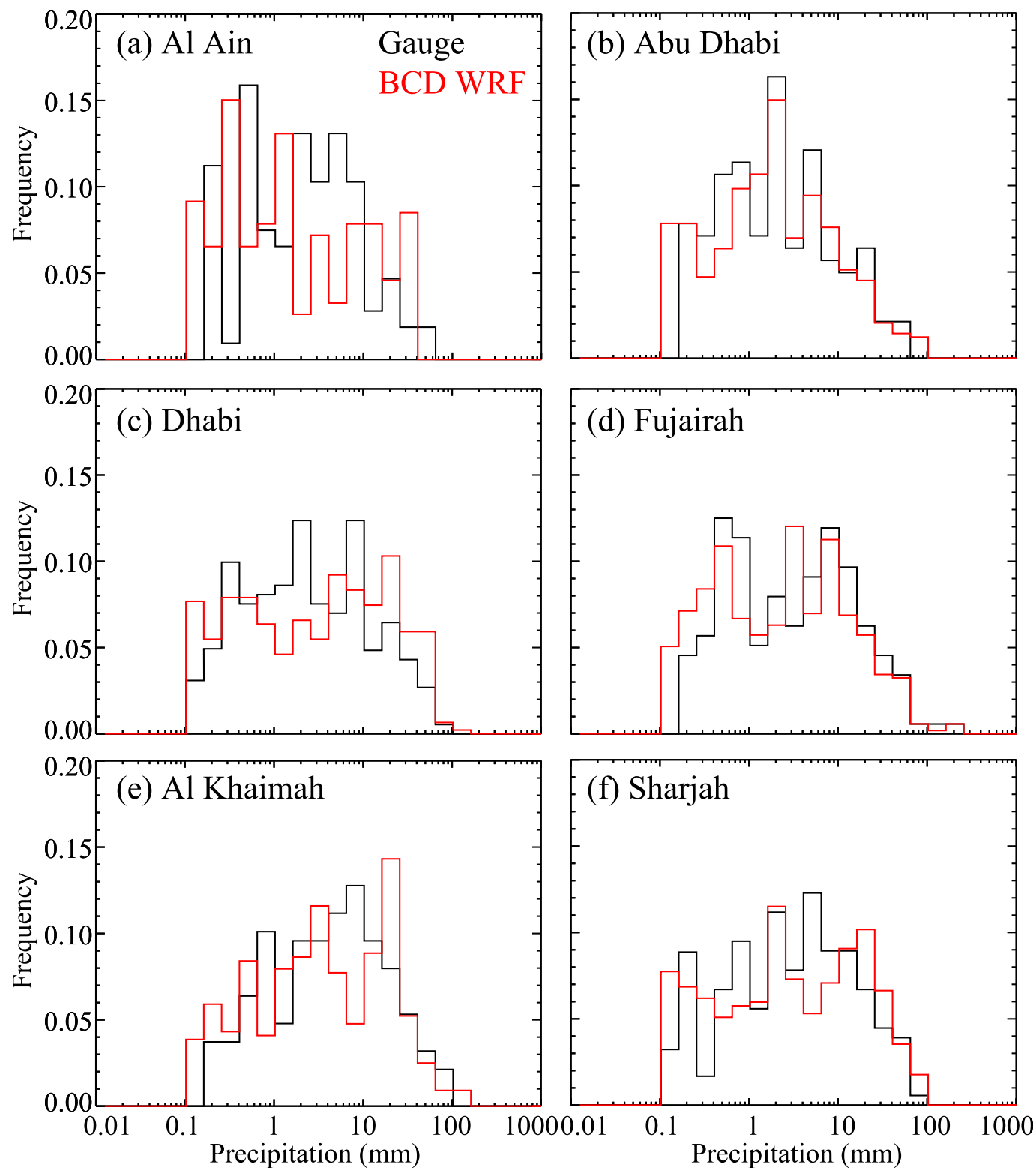

FIG. 8. Frequency of daily precipitation from the rain gauge (black) measurements at six major airports in UAE, and the BCD WRF simulation (red; domain 3). Data from May 1994 to December 1999 are used for the Al Ain International Airport, and data from January 1990 to December 1999 are used for the other five stations.

shown). Since this study aims to examine the precipitation climatology, investigating the mean seasonal and annual precipitation is appropriate for this goal.

\section{c. Precipitation variability}

To study the potential changes in the precipitation climatology in a changing climate, it is also important to evaluate the model's capability in simulating the temporal variability of precipitation at different locations. Direct comparison of the time series of precipitation shows significant differences between benchmark simulation (or observation) and BCD WRF simulation since the lateral boundary conditions are different. Therefore, we plot the frequency distributions of the daily precipitation using the gauge data and BCD WRF simulation (domain 3) as shown in Fig. 8. Differences clearly exist between the gauge measurements and the BCD WRF simulation, but generally the BCD WRF can capture the variability range of the daily precipitation, as the width and magnitude are consistent between the observation and the model results. 

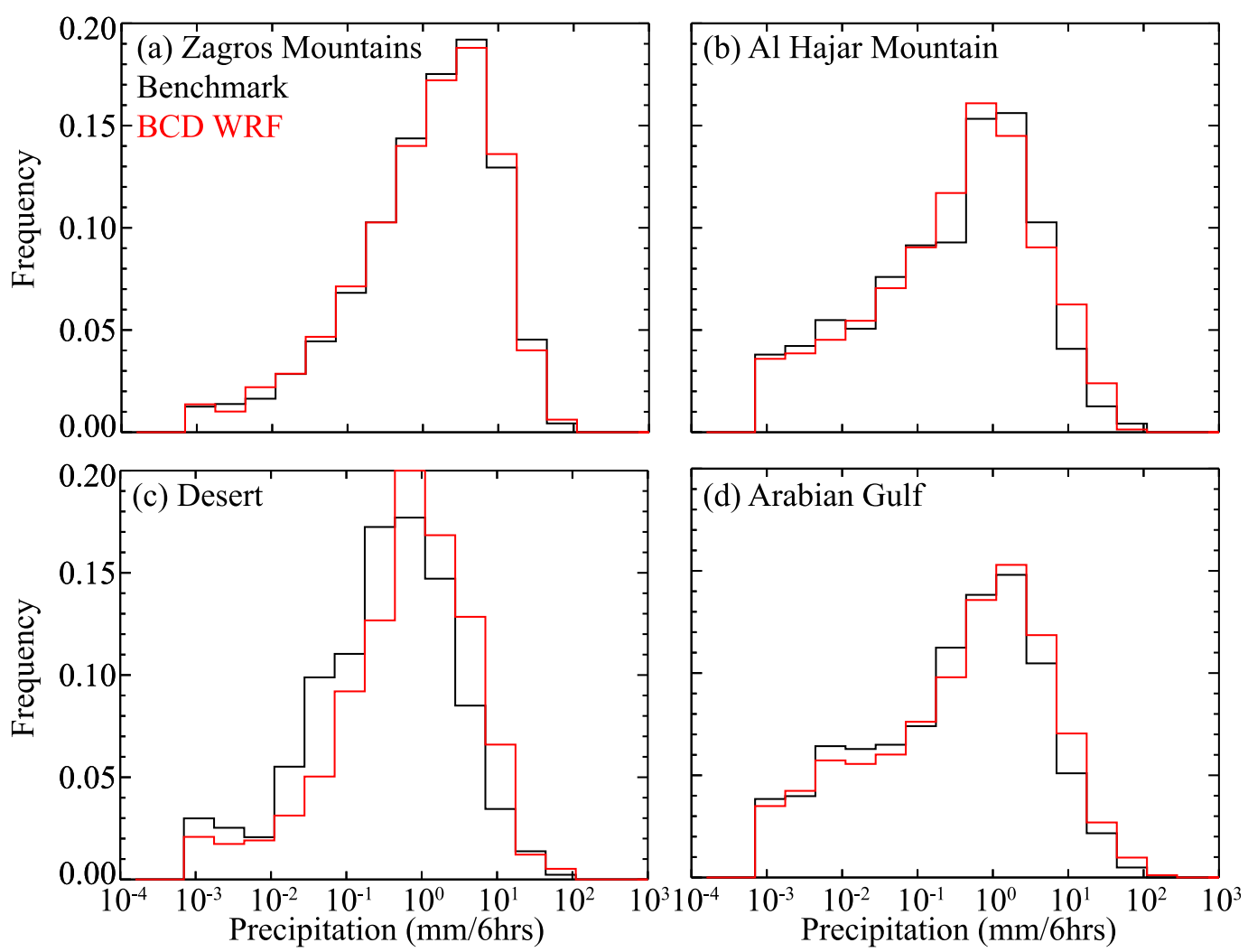

FIG. 9. Frequency of the precipitation rate from 1986 to 2005 modeled by the benchmark (black) and BCD WRF (red) simulations in domain 2 at the (a) Zagros Mountains, (b) Al Hajar Mountains, (c) Desert, and (d) Arabian Gulf.

We also compare the frequency distributions of precipitation rate from 1986 to 2005 at four different locations representative of typical climate regimes in the Arabian Gulf region (marked as crosses in Fig. 1c) in Fig. 9 using the data from the benchmark and BCD WRF simulations (domain 2). As seen from the figure, the BCD WRF simulation captures the precipitation variability at these locations, as the maximum frequency and the width of the frequency distribution are similar. In the desert area and the Arabian Gulf, the BCD WRF produced slightly higher precipitation rates than the benchmark simulation, but the characteristics of the variability and the minimum and maximum precipitation rate are well captured.

Because the BCD WRF performs well in modeling the precipitation distribution and variability, we can further evaluate the wet index and the maximum dry spell, which are two widely used climate indices (e.g., Schmidli and Frei 2005; Serra et al. 2014). Here, the wet index is defined as the annual number of days with daily precipitation greater than $1 \mathrm{~mm}$ from 1990 to 2005 . The maximum dry spell is defined as the longest run of consecutive days with daily precipitation less than
$0.1 \mathrm{~mm}$ from 1990 to 2005. As shown in Fig. 10, both simulations indicate that the wet index is higher over mountains ( $\sim 50-180$ days) than the plain area $(\sim 0$ 20 days), and the maximum dry spell is shorter over mountains than the plain area. In the desert area of Saudi Arabia, eastern Egypt, and eastern Iran, there are few wet days. Over the Arabian Sea, the maximum dry spell is approximately 100 days, whereas over the Arabian Gulf the maximum dry spell is longer than 200 days. The difference in the wet index between the benchmark and BCD WRF simulations (Fig. 10c) is smaller than 10 days in most of the areas, and on average the difference is approximately 1 day $(4.87 \%)$. The distribution of difference in the maximum dry spell between the two simulations is noisy (Fig. 10f), probably because of the different meteorological events between the reanalysis and the CESM data. The maximum dry spell can be significantly affected by individual precipitation events, and thus is sensitive to the driving datasets. For example, the patterns of the maximum dry spells are different over the ocean area east of the Al Hajar mountain, but the wet indices are similar, as there was a significant drought event in this 

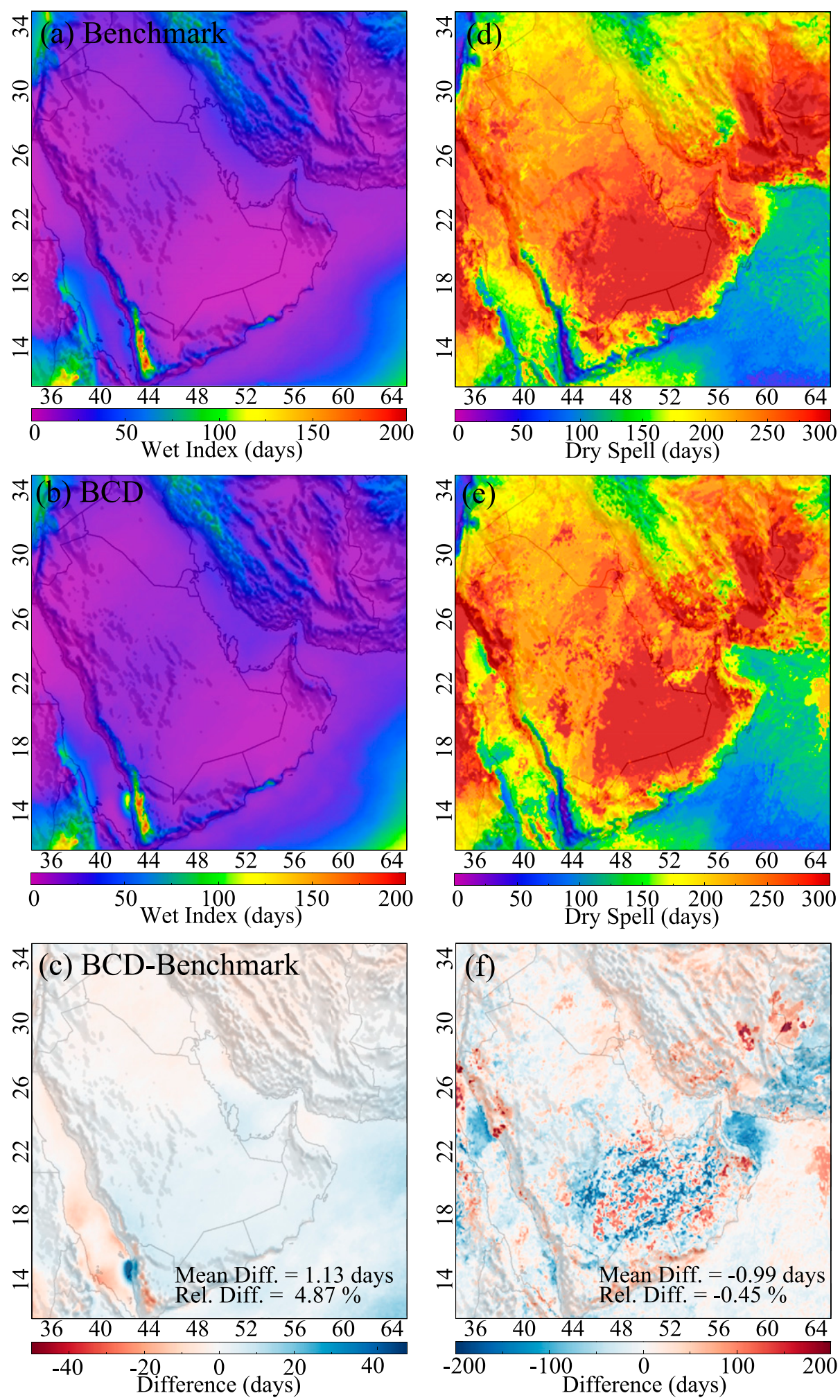

FIG. 10. Annual wet index in domain 2 estimated by the (a) benchmark and (b) BCD WRF simulation, and (c) their differences. (d)-(f) As in (a)-(c), but for the maximum dry spell from 1986 to 2005 . 
area in the benchmark model but not in the BCD WRF Model. However, the average difference between the two simulations is small, which is only -1 day $(-0.45 \%)$, and if the median values and $25 \mathrm{th} / 75$ th percentiles of the dry spell are plotted instead of the maximum values, the noisy pattern in Fig. 10f disappears.

In short, according to Figs. 3-10, the BCD WRF simulations perform well in modeling the mean seasonal precipitation distribution as well as the precipitation variability in the Arabian Gulf region, providing confidence in using the model outputs to study the potential changes in a warmer climate. However, it should be noted that there are many ways that the model limitations can produce the biases. First, the $4-\mathrm{km}$ grid spacing is able to adequately represent mesoscale terrain and associated precipitation distribution. However, such resolution fails to depict properly small-scale topographical variations such as narrow valleys and ridges, and thus the corresponding fine structure of precipitation distribution, as evidenced by a comparison between 4- and $1.33-\mathrm{km}$ models over North America (Jing et al. 2017). Second, 4-km grid spacing is unable to fully resolve small-scale convective processes, and this would likely result in larger uncertainties in summer precipitation than wintertime precipitation (Liu et al. 2017; Jing et al. 2017). Third, precipitation is influenced by the uncertainties in the treatment of cloud microphysical processes. In particular, aerosol-cloud interactions are completely missing in the present simulations because the employed microphysics scheme uses a constant number of cloud droplets. In addition, the current model setup does not carefully consider the spatial and temporal variations of aerosols and their interactions with radiation. The poor representation of both aerosolradiation and aerosol-cloud interactions could lead to substantial precipitation biases in regions of high aerosol concentration (Yun et al. 2020). Khain et al. (2015) also showed that the uncertainty in microphysics is one of the most important reasons for large biases in individual precipitation events.

\section{Future changes predicted by the bias-corrected CESM driven WRF simulation}

\section{a. Near-surface temperature and precipitation}

The 10-yr mean seasonal near-surface temperature modeled by the convection-permitting BCD WRF simulations in domain 3 for the retrospective and future climates, as well as the changes, are shown in Fig. 11 for dry and wet seasons respectively. It is shown that the warming signal varies seasonally and geographically. Not surprisingly, the near-surface temperature is lower in the wet season than in the dry season, and the temperature is higher (lower) over the ocean than over the land in the wet (dry) season. Most of the continental areas undergo a remarkable warming of approximately $3^{\circ} \mathrm{C}$ throughout the year (Figs. 11c,f). The most significant increase in near-surface temperature is found over the northern region of the model domain, particularly the northern Zagros Mountains, consistent with previous studies that show the rate of warming amplifies with elevation (e.g., Pepin et al. 2015). On average, for the RCP8.5 emission scenario, the 2-m temperature from 1990-99 to 2065-74 in the Arabian Gulf region increases by $3.15^{\circ} \mathrm{C}(16.69 \%)$ and $3.11^{\circ} \mathrm{C}(10.43 \%)$ in the wet and dry seasons, respectively.

As the temperature increases, more water vapor evaporates from the surface. Previous studies suggested the global mean precipitation amount and the extreme precipitation events would increase by $\sim 2 \%$ and $\sim 7 \%$ per degree Celsius of temperature increase, respectively (Held and Soden 2006; Prein et al. 2017). However, due to the poleward shift of the storm tracks, the moisture enhancement in convergence zones, and the changes in quasigeostrophic circulations, the subtropical arid area would become drier, while the high latitudes and tropical areas would be wetter (Meehl et al. 2007; Chou et al. 2009). Figure 12 shows the BCD WRF modeled wet and dry season precipitation around years 1995 and 2070, as well as the changes. With a higher resolution $(4 \mathrm{~km})$, the changes in precipitation over complex terrain and that initiated from convection can be well simulated (Figs. 12c,f). In the wet season, the precipitation increases over the Arabian Gulf and the Al Hajar Mountains, and decreases over most of the continental area. The most dramatic decline in wet season precipitation is found over the Zagros Mountains. In the dry season, the precipitation increases over the ocean, the southern Zagros Mountains, and the Al Hajar Mountains in a warmer climate, and decreases over the northern Zagros Mountains. On average, in both the wet and dry seasons, the precipitation in the model domain increases in a warmer climate, but compared to the wet season, the absolute change in precipitation in dry season is weak.

Previous GCM studies suggested that precipitation would be intensified in a warmer climate in most areas around the world (Meehl et al. 2007; Allan and Soden 2008). With the advantages of convection-permitting modeling, we can better detail the changes in precipitation intensity in the Arabian Gulf region. As shown in Fig. 13, on average, the precipitation intensity increases by $0.46 \mathrm{~mm}(6 \mathrm{~h})^{-1}(23.14 \%)$ in the wet season (Fig. 13c) and $0.62 \mathrm{~mm}(6 \mathrm{~h})^{-1}(36.40 \%)$ in the dry season (Fig. 13f), qualitatively consistent with that 

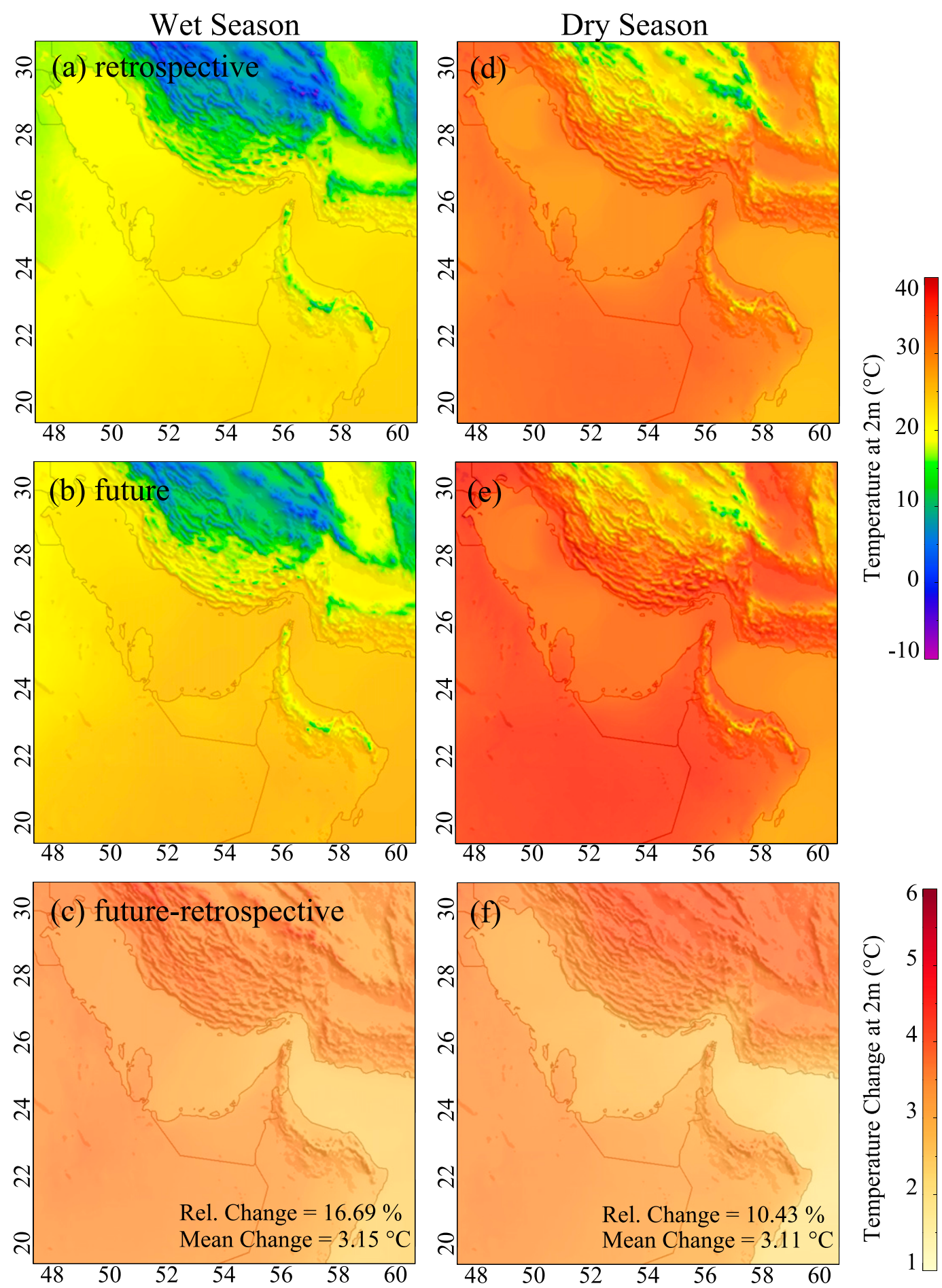

FIG. 11. Temperature at $2 \mathrm{~m}$ in (left) wet and (right) dry seasons in domain 3 for (a),(d) retrospective and (b),(e) future climate, and (c),(f) their changes estimated by BCD WRF simulations.

suggested by GCM simulations. However, the changes in precipitation intensity vary geographically. In the wet season, the Arabian Gulf and the southern Zagros Mountains experience more intense precipitation in a warmer climate. In other areas of the Arabian Gulf region, the precipitation is either slightly intensified or weakened. In the dry season, the substantial increase in the mean precipitation intensity in the Arabian Gulf 

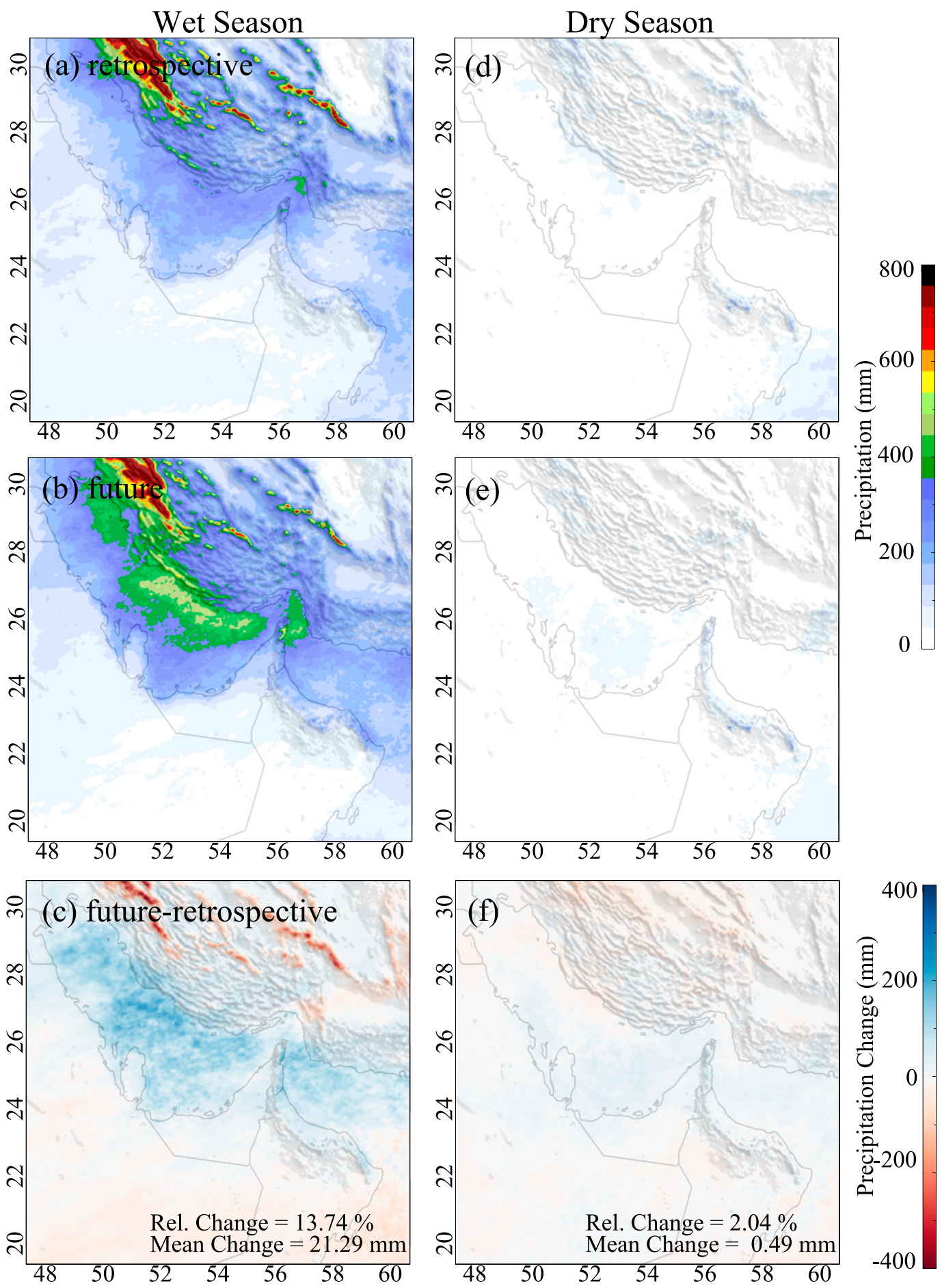

FIG. 12. Precipitation in (left) wet and (right) dry seasons in domain 3 for (a),(d) retrospective and (b),(e) future climate, and (c),(f) their changes estimated by BCD WRF simulations.

region is strongly affected by individual precipitation events; a few more extreme events in a warmer climate would result in significant changes in the precipitation intensity since there are only a few precipitating events in a dry season according to the gauge measurements. As seen in Fig. 13f, the precipitation intensity increases quite significantly over the Arabian Gulf. In other areas, especially over the land, the distribution of the 

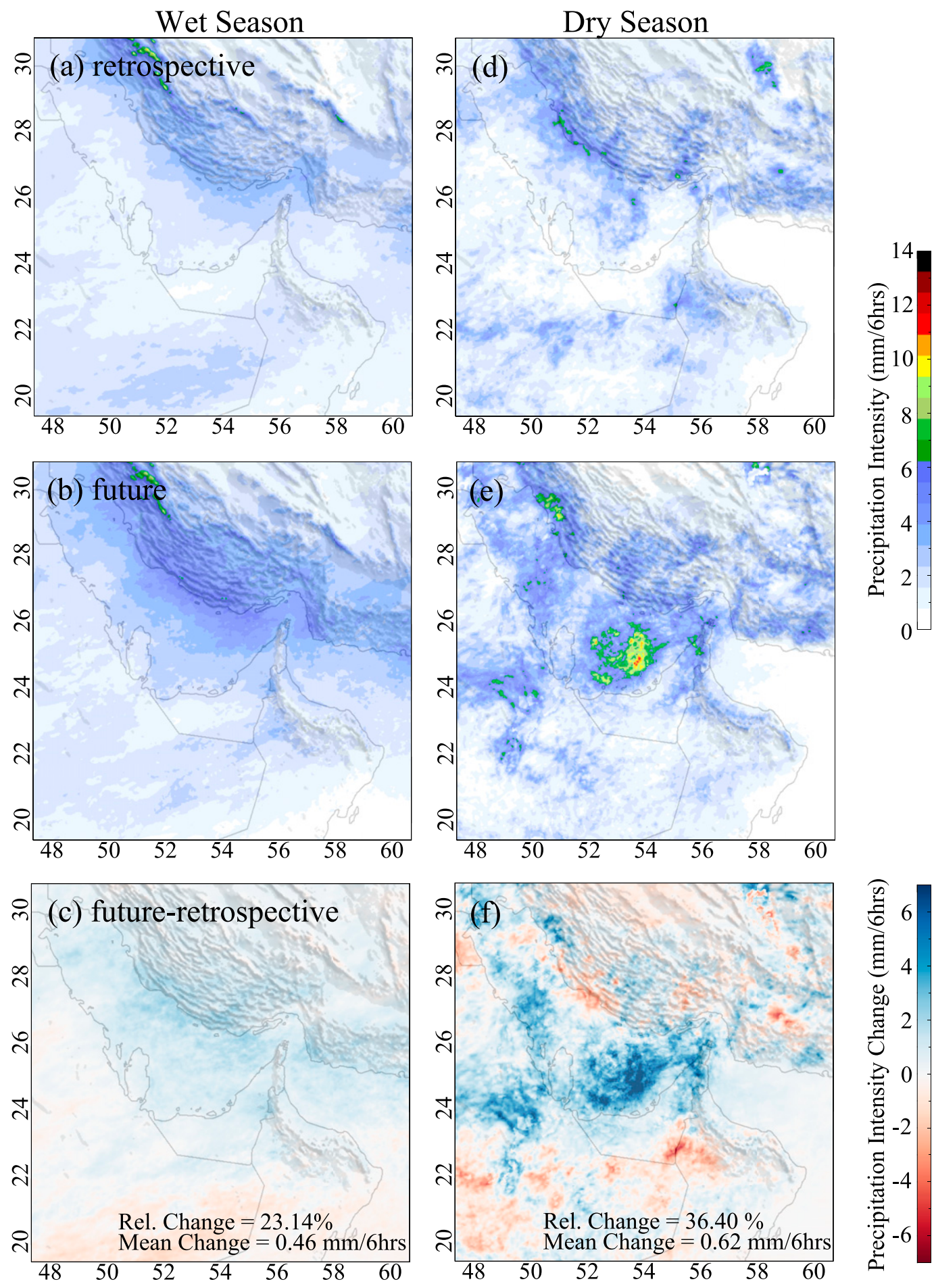

FIG. 13. Precipitation intensity in (left) wet and (right) dry seasons in domain 3 for (a),(d) retrospective and (b),(e) future climate, and (c),(f) their changes estimated by BCD WRF simulations.

changes in precipitation intensity is noisy, indicating the impact of individual events. This issue will be further addressed in a future study focusing on precipitation extremes. Although the dry season achieves stronger precipitation intensity enhancement than the wet season in a warmer climate, the increase in precipitation amount is less in the dry season than the wet season (Figs. 12c,f). 
Figure 14 shows the BCD WRF modeled wet index and the maximum dry spell for the retrospective and future climates, as well as their changes. The wet index decreases in most areas of the model domain except for the Arabian Gulf and eastern Al Hajar Mountains. The most significant decrease occurs over the Zagros Mountains. In the desert area south of the Arabian Gulf, the wet index decreases by approximately 4 days. According to Figs. 11-14, it can be found that both the precipitation intensity and wet index increase over the Arabian Gulf in a warmer climate, resulting in an increase in the precipitation amount, while over the land the decrease in the wet index (i.e., precipitation events) cancels the effect of precipitation intensity increase, resulting in a decrease in the precipitation amount in a warmer climate. The distribution of change in the maximum dry spell within 10 years (Fig. 14f) appears to be noisy because it is strongly affected by individual precipitation events. However, we can see that in most parts of the Arabian Gulf region, the maximum dry spell increases, especially near the margin of the tropics, maybe because of the increase in low-level static stability and lack of lifting mechanisms (Chou et al. 2009; shown later in section $4 \mathrm{~b}$ ). On average, the maximum dry spell increases by 25 days $(10.67 \%)$, and this value is larger than the mean difference between the BCD and benchmark WRF simulation (Fig. 10f), suggesting the changing signal is of significance, although the pattern is highly variable.

\section{b. Ambient stability}

The apparent opposite signs of the precipitation changes over the ocean and land can be revealed from the changes in convective available potential energy (CAPE) and convective inhibition (CIN). Here, both CAPE and CIN are calculated for the lowest $100-\mathrm{hPa}$ atmosphere, and is referred to the mixed-layer CAPE (MLCAPE) and mixed-layer CIN (MLCIN). MLCAPE represents the convective energy available to the lowlevel parcel while being lifted to the level of free convection. MLCIN represents the energy inhibiting convection, and is often used to investigate whether a given environment is favorable for deep convection (Rasmussen et al. 2020). In an environment with weak inhibition (MLCIN $>-50 \mathrm{~J} \mathrm{~kg}^{-1}$ ) and high MLCAPE, surface heating can usually break the capping inversion and convective events likely occur. Environments with moderate inhibition (typically between -200 and $-50 \mathrm{~J} \mathrm{~kg}^{-1}$ ) can be overcome with stronger lifting of air parcel that is usually accompanied by strong MLCAPE, which leads to heavy precipitation (Rasmussen et al. 2020). If the MLCIN is too strong (MLCIN $<-200 \mathrm{~J} \mathrm{~kg}^{-1}$ ), or the ambient environment is too dry to have effective MLCAPE, convection is suppressed.

Figure 15 shows the mean MLCAPE (left column) and MLCIN (right column) for the retrospective and future climates, as well as their differences (future retrospective). Clearly, the MLCAPE (Figs. 15a,b) is higher over the ocean than over the land because of the stronger evaporation over the water surface, providing more convective energy. Larger MLCAPE is often associated with larger MLCIN (Fig. 15d). Over the ocean, the MLCIN has moderate strength, from approximately -100 to $-130 \mathrm{~J} \mathrm{~kg}^{-1}$. Over the mountains and desert areas, the MLCAPE and MLCIN are both low because of the dry low-level conditions. In the model domain, no area is found to have high MLCAPE but low MLCIN values, indicating the general high static stability. In a warmer climate, the MLCAPE and MLCIN are strengthened over the ocean (Figs. 15c,f). This is not surprising based on the fact that the saturation vapor pressure increases exponentially with increasing temperature. Therefore, assuming the relative humidity remains similar, a warmer and moister environment will result in stronger MLCIN and MLCAPE (Prein et al. 2017; Rasmussen et al. 2020). Due to the increase in MLCIN, weak and moderate convective events would be more likely suppressed in the future. However, more deep convective events may occur due to stronger surface heating. Over the land, the mean changes in MLCAPE and MLCIN are small. There are two possible reasons. First, the atmosphere gets warmer significantly over the land, but the moisture enhancement is weak, and consequently the relative humidity decreases. Second, cases with effective convective energies (i.e., positive MLCAPE and negative MLCIN) rarely occur, even in a warmer and moister climate (Figs. 15b,e), and thus there is no obvious strengthening of the average MLCAPE and MLCIN over the land.

Analyses of the thermodynamics conditions indicate that the low-level (lowest $100 \mathrm{hPa}$ ) relative humidity has little change over both land and ocean (not shown). Therefore, the first possibility (relative humidity decreases) cannot explain the insignificant change in the MLCAPE and MLCIN over the land. The main difference in the thermodynamic conditions over the land and ocean is the low-level humidity, which is much higher over the ocean than land. The ambient condition over the land is so dry that there is no effective convection energy overall (i.e., MLCAPE $=0$ ) in both retrospective and future periods. While over the ocean, the relatively high low-level humidity provides a more convection-favorable thermodynamic condition. 

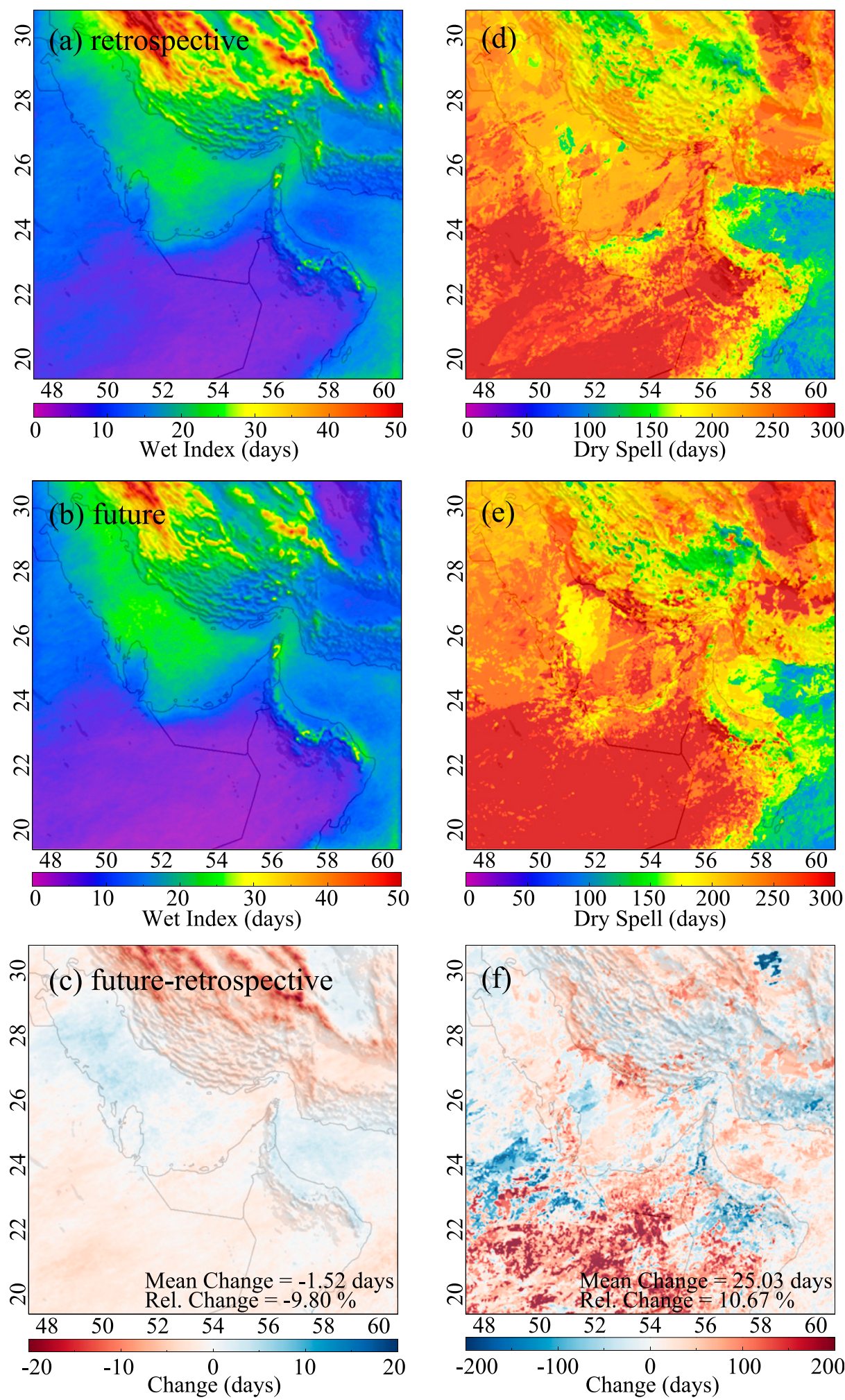

FIG. 14. (left) Mean annual wet index and (right) the maximum dry spell within 10 years in domain 3 for (a),(d) retrospective and (b),(e) future climate, and (c),(f) their changes estimated by BCD WRF simulations. 

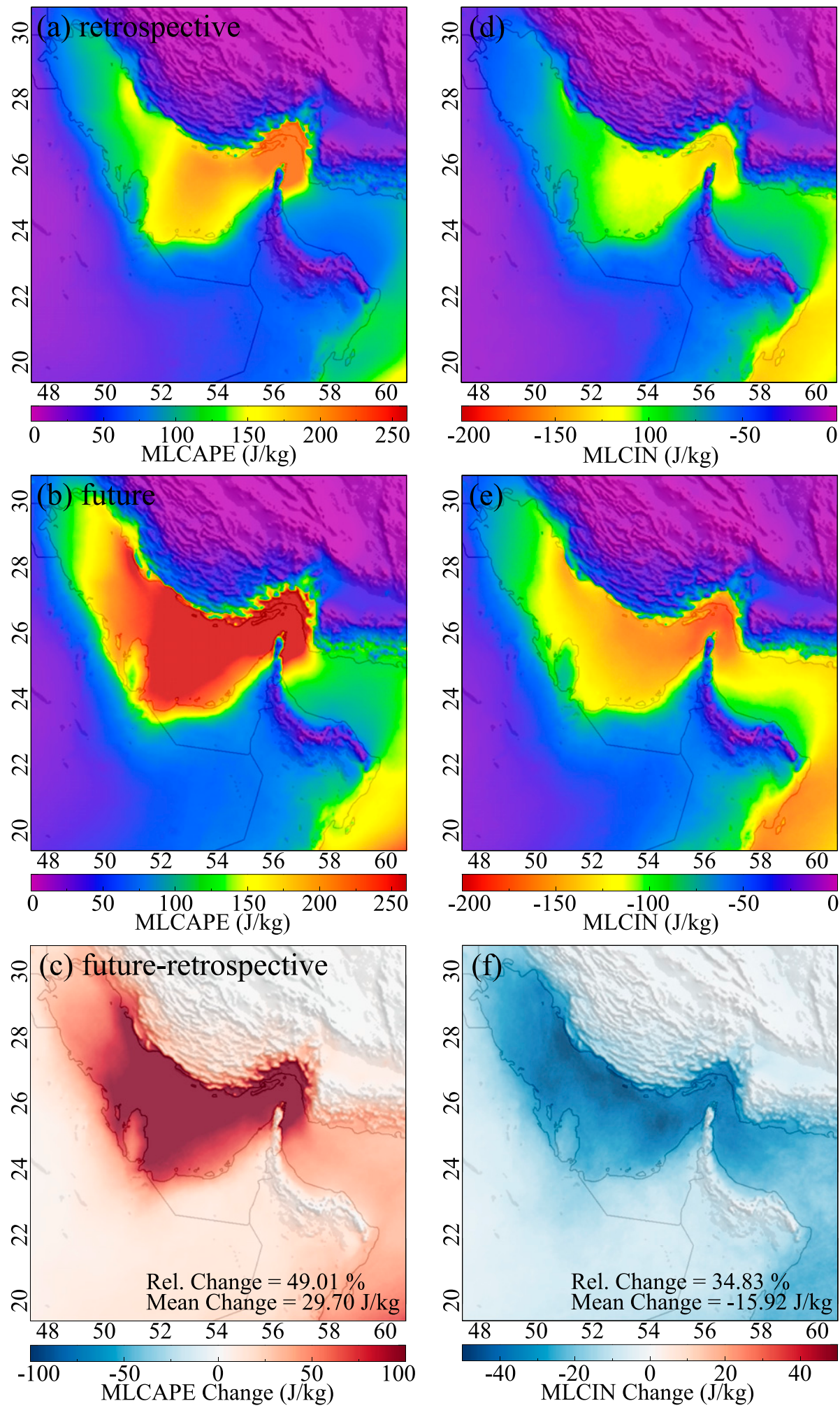

FIG. 15. Mean (left) MLCAPE and (right) MLCIN in domain 3 for (a),(d) retrospective and (b),(e) future climate, and (c),(f) their changes estimated by BCD WRF simulations. 

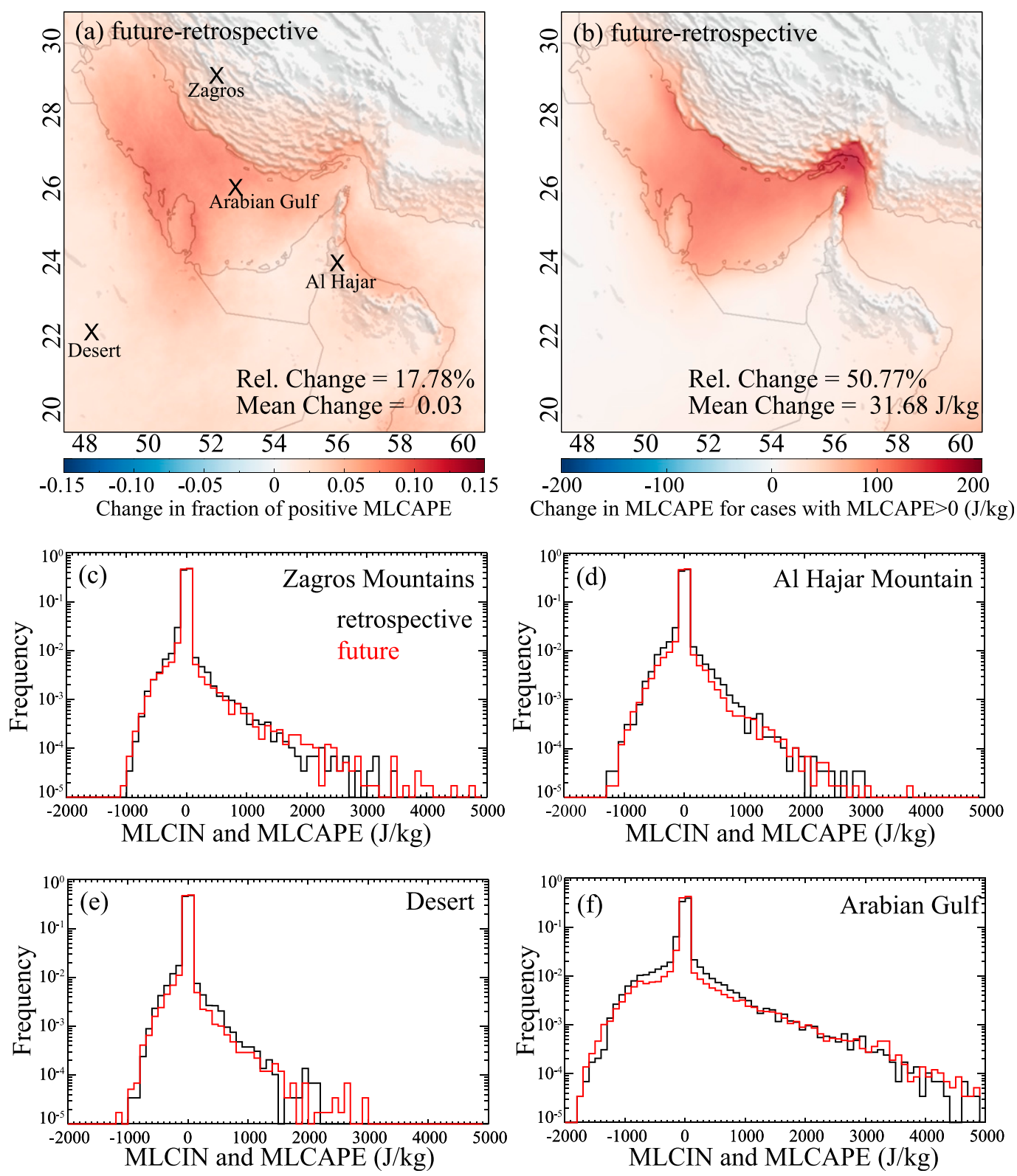

FIG. 16. (a) Changes in the fraction of cases with positive MLCAPE (future - retrospective) predicted by the BCD WRF simulations. (b) Changes in the mean MLCAPE distribution for cases with positive MLCAPE. (c)-(f) Frequency distributions of MLCIN and MLCAPE at the Zagros Mountain, Al Hajar Mountains, Desert, and Arabian Gulf for retrospective and future climate. The four locations are marked by the crosses in (a).

Figure 16 shows the changes in the fraction of cases with positive MLCAPE (future - retrospective) predicted by the BCD WRF simulations (Fig. 16a), changes in the mean MLCAPE for cases with positive MLCAPE only (representing the "intensity" of MLCAPE; Fig. 16b), and the frequency distribution of MLCIN and MLCAPE for the Zagros Mountains, Al Hajar Mountains, Desert, and Arabian Gulf subregions (Figs. 16c-f). Over the ocean, the fraction of cases with positive MLCAPE increases in a warmer climate, indicating more convective events. The mean MLCAPE for cases with positive MLCAPE also increases over the ocean, indicating the strengthening of convective events. The increase in the mean MLCAPE over the ocean can be further confirmed by the broadening of the frequency distributions of MLCAPE and MLCIN (Fig. 16f). Over the land, the fraction of cases with positive MLCAPE and the mean MLCAPE both have little increase 
(Fig. 16b). Although the frequency of MLCAPE and MLCIN over the land slightly broadens as the climate gets warmer (Figs. 16c-e), cases with effective convective energy are so limited that a few more cases with larger MLCAPE will not lead to an increase in the mean MLCAPE as significantly as that over the ocean.

Other thermodynamics factors could influence the convective events too, thus affecting the precipitation distribution. For example, the stratification over convectionrelevant depths controls the development and life cycle of convective cloud. If the potentially unstable layer over the Arabian Gulf is overlain by equally buoyant air, the vertical exchanges would be inhibited even if there was strong MLCAPE. Another factor that may affect the development of convective cloud is the relative humidity in the troposphere; on average the relative humidity has no change in the troposphere, but we do see variations of relative humidity at different levels (i.e., some levels become dryer while others become wetter). In such a situation, the mixing of cloud and ambient air, especially when the entrainment is strong, would have significant impacts on the cloud life cycle and precipitation formation.

\section{c. Low-level wind field and vapor flux}

Other than the thermodynamic impact, the dynamics, which is primarily controlled by the large-scale circulation, and strongly affected by the local circulation (e.g., breezes), also plays important roles in the potential changes in precipitation in a warmer climate, especially over mountains and in the vicinity of water bodies. Jing et al. $(2018,2019)$ showed that the low-level mountainnormal wind speed is the dominant factor controlling orographic precipitation, for both the precipitation intensity and the precipitation distribution across a mountain range. Statistically, a stronger wind results in heavier precipitation that is distributed more evenly across leeward and windward sides, whereas a weaker wind typically is associated with weaker orographic precipitation and larger upwind precipitation fraction. Stronger winds produce deeper upwind moist ascent, which leads to deeper clouds (Colle 2004; Jing et al. 2018). Other studies also suggest that the crossmountain wind speed and the precipitation intensity are highly correlated (e.g., Colle 2004; Yuter et al. 2011; Luce et al. 2013). Figure 17 shows the wind field and horizontal water vapor flux at $1 \mathrm{~km}$ above ground level modeled by the BCD WRF simulations for the retrospective and future climates, as well as their changes. In the wet season (Fig. 17a), the prevailing wind is westerly north of the Arabian Gulf, and the water vapor mainly comes from the Arabian Gulf and Mediterranean Sea. The desert area south of the Arabian Gulf is controlled by high pressure, as indicated by the anticyclone. In the dry season (Fig. 17d), the prevailing wind is mainly northerly in the model domain; the average low-level vapor flux has approximately the same magnitude as that in the wet season, but the higher temperature and lack of lifting mechanisms in the dry season lead to fewer precipitation events. In a warmer climate, the low-level water vapor mixing ratio increases in both wet and dry seasons, resulting in stronger average horizontal vapor flux. However, because of the changes in dynamics, particularly the wind field, the vapor flux shows only small increases, or even decreases over the mountain areas (Figs. 17c,f). In addition, the declining low-level cross-mountain wind speed results in weaker terrain-induced ascent (Smith and Barstad 2004; Colle 2004; Jing et al. 2018). Therefore, the precipitation decreases over mountains in a warmer climate (Fig. 12).

To summarize, the future changes in precipitation in a warmer climate are determined by both thermodynamic and the dynamic impacts. The thermodynamic impact, which is controlled by the temperature and moisture increases, results in clear geographic differences in the precipitation changes (i.e., an increase over the ocean but minimal changes over the land). The dynamic impact, which is controlled by the changes in large-scale circulation and atmosphere-ocean teleconnections, is also important to the future changes in precipitation distribution, particularly the decrease in precipitation over mountains. Moreover, the changes in local circulations, which may be induced by the composite impact of thermodynamics and large-scale dynamics, could significantly affect regional cloud and precipitation formation, such as in the vicinity of water bodies.

\section{Discussion}

Based on the analyses above, we see the BCD WRF simulations can well capture the regional climatology in the Arabian Gulf region, and can be a useful tool to investigate the potential changes in the future at a convection-permitting resolution. The BCD WRF simulations have the advantage of containing both the changes in thermodynamic properties and the large-scale circulations caused by natural and anthropogenic emissions at a convection-permitting resolution, and this is preferred for studying the future climate change. This is particularly important given that, in the global-scale perspective, the tropical- and global-average extreme precipitation relation to global-mean surface temperature occurs in a nonlinear fashion (Pendergrass et al. 2019). Previous studies using the PGW approach can 


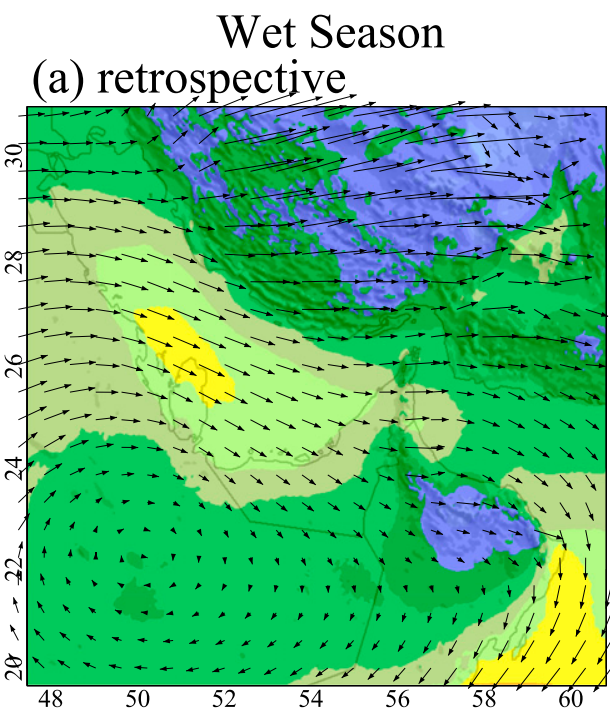

(b) future

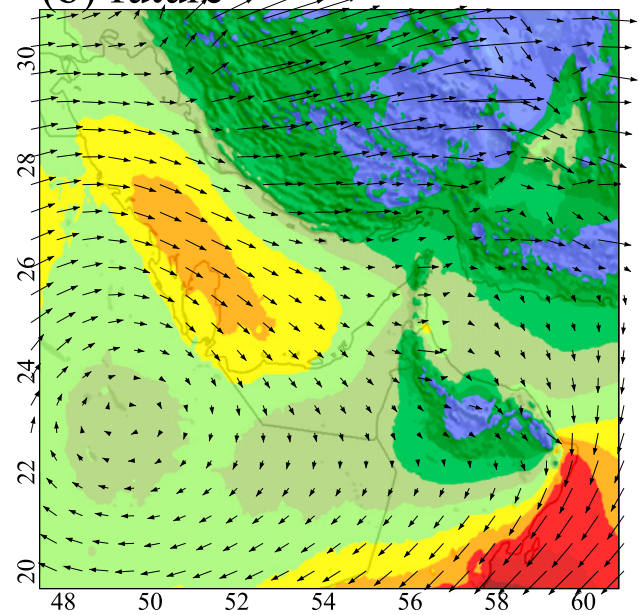

(c) future-retrospective

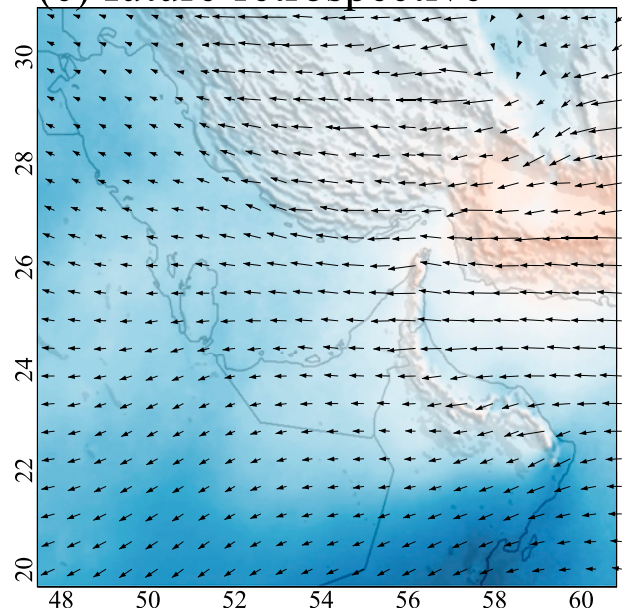

(d)

\section{Dry Season}

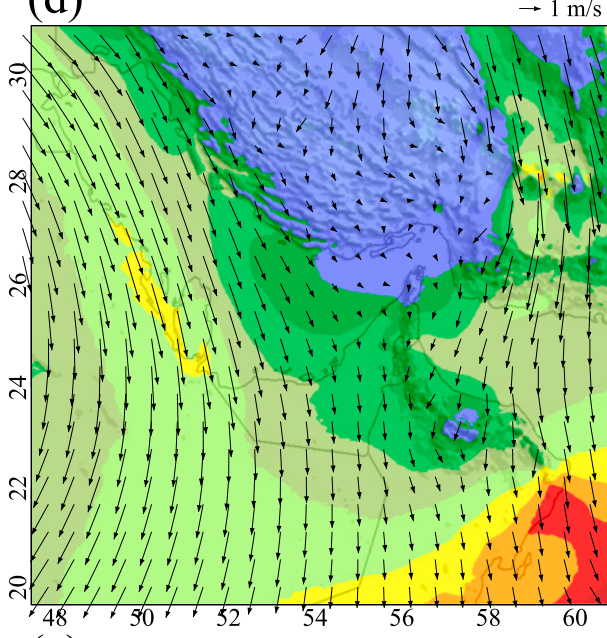

(e)

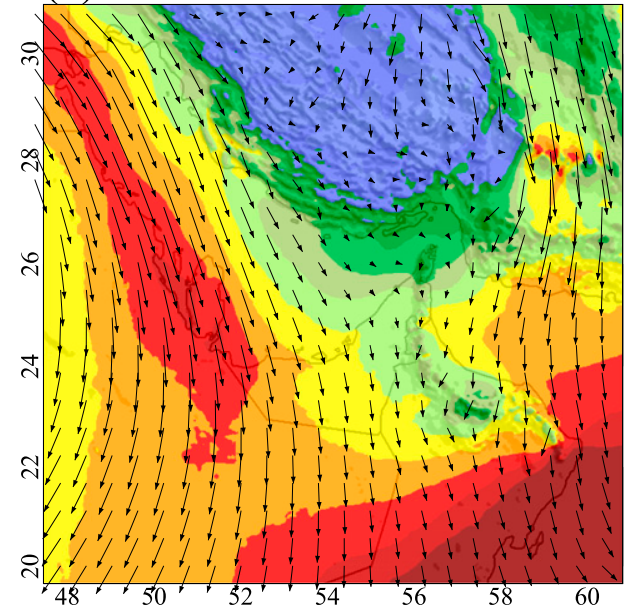

(f)

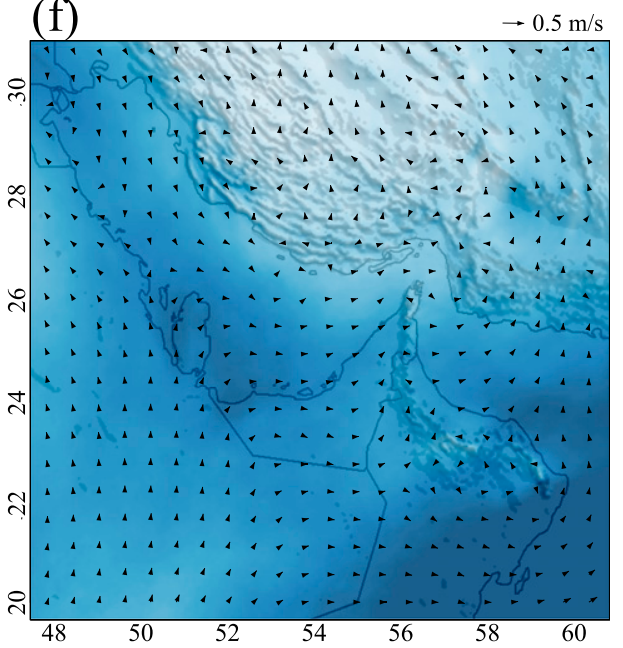

FIG. 17. Horizontal water vapor flux (colored) and wind (arrow) at $1 \mathrm{~km}$ AGL in (left) wet and (right) dry seasons in domain 3 for (a),(d) retrospective and (b),(e) future climate, and (c),(f) their changes estimated by BCD WRF simulations. 
reveal the impact of the thermodynamic changes, but not the dynamics. Even though some dynamic components, such as the mean wind speed and direction, are modified in the PGW simulations, the meteorological events remain the same in the retrospective and future climate, so the impact of dynamics cannot be fully revealed. In addition, since the GCM data are dynamically downscaled at a convection-permitting resolution, many of the predictable physical processes of greenhouse gasforced climate change can be represented, such as the small-scale processes over complex terrain and convective systems; the accuracy of convective events can also be improved without using the error-prone cumulus parameterizations. These processes may be misrepresented in statistical downscaling techniques and in RCMs with relatively low resolutions.

The disadvantage of the BCD WRF simulation is that the lateral boundary condition is provided by the CESM data. Although the mean biases have been corrected in the CESM data, they cannot represent the real meteorological events. Therefore, the modeled results can only be used to investigate the regional climatology, not individual historical events. In addition, like other GCMs, CESM has uncertainties in modeling the future climate due to the inaccurate representations of subgrid physical processes. One way to reduce the uncertainty is to conduct a set of RCM simulations driven by different bias-corrected GCMs, and find the range of potential future changes based on multisimulation outputs (Coppola et al. 2018). However, this approach requires substantial computational resources. It is inappropriate to conduct a WRF simulation driven directly by the ensemble means of multiple GCMs because this will smooth out the weather events. The essential way to improve the GCMs is a better understanding of the physical processes in the atmosphere system, which requires more observations and using GCMs with reduced dependence on subgrid parameterizations where possible and accounting for their uncertainty where not (Palmer and Stevens 2019).

In the Middle East, dust is of great importance for the global and regional climate. First of all, future changes in dust concentration in the air and distribution over the land have significant radiative impact since it reflects solar radiation. Additionally, dust particles, as efficient ice nuclei at temperatures lower than $-15^{\circ} \mathrm{C}$, strongly influence ice formation and precipitation efficiency. Moreover, the long-range transport of dust from the Middle East may affect the energy balance and water cycle globally. Therefore, aerosol-aware RCM simulations are necessary to better understand future climate change under a global warming scenario.
With the advantages and disadvantages clarified, it can be concluded that the BCD WRF simulation is one of the pathways to study the regional climate under a global warming scenario. A convection-permitting RCM driven by reanalysis data is recommended for retrospective periods because it can represent real weather events, whereas the BCD RCM would be more appropriate for future climatic projections because it includes both the thermodynamic and dynamic impacts, but careful verifications of the variables of interest are necessary.

\section{Conclusions}

In this study, the regional climate of the Arabian Gulf region is modeled using a set of WRF-based RCM simulations. The precipitation climatology modeled by the retrospective BCD WRF simulation is evaluated using the TRMM product, the rain gauge data at six major airports in the United Arab Emirates (UAE), and the baseline dataset from the benchmark WRF simulation. The changes in near-surface temperature, precipitation, and ambient conditions are investigated using the outputs from the convection-permitting BCD WRF simulations for the retrospective and future periods. The main findings are as follows:

1) Cross-validations among the TRMM, gauge, benchmark, and BCD WRF simulations indicate that the BCD WRF simulation can well reproduce the seasonal precipitation distributions, mean monthly precipitation, precipitation variability, wet index, and maximum dry spell. The correlation coefficients of seasonal precipitation between the BCD WRF and gauge measurements are higher than 0.8 . WRF can better resolve the terrain-related texture of precipitation distribution than TRMM because of its higher resolution. The differences in precipitation between TRMM and the WRF simulations are due to the composite impact of the model uncertainties and the limitations of TRMM retrieval. The differences between the benchmark and BCD WRF simulations are mainly attributed to the large-scale circulations and meteorological events that differ in the reanalysis and CESM datasets.

2) For the RCP8.5 emission scenario, most of the continental areas undergo a remarkable warming of approximately $3^{\circ} \mathrm{C}$ by 2070 . The most significant increase in near-surface temperature is found in the northern region of the model domain, particularly the northern Zagros Mountains. The precipitation increases over the Arabian Gulf and the Al Hajar Mountains, and decreases over most of 
TABLE A1. Description of bias-corrected variables in the 6-hourly intermediate files.

\begin{tabular}{|c|c|c|}
\hline Variables & Unit & Description \\
\hline SKINTEMP & $\mathrm{K}$ & $\begin{array}{l}\text { Monthly average skin temperature expressed every } 6 \mathrm{~h} \text { (e.g., all time steps in January } 2002 \\
\text { are the same, then SKINTEMP changes for February 2002, etc). This variable is relatively } \\
\text { unimportant as it is used only to initialize the land surface model. }\end{array}$ \\
\hline TAVGSFC & $\mathrm{K}$ & $\begin{array}{l}\text { This field is identical to SKINTEMP but is used to initialize surface temperatures for inland } \\
\text { lakes if that option is used. The use of a monthly average temperature field (expressed 6- } \\
\text { hourly) can keep the lake surface temperatures from undergoing large diurnal } \\
\text { fluctuations. }\end{array}$ \\
\hline SST & $\mathrm{K}$ & $\begin{array}{l}\text { Daily sea surface temperature expressed every } 6 \mathrm{~h} \text { (e.g., all time steps on } 1 \mathrm{Jan} 2002 \text { are the } \\
\text { same, then SST changes for } 2 \text { Jan 2002). The SST field is interpolated from the ocean } \\
\text { model (POP) output from CESM. }\end{array}$ \\
\hline ST000010 & $\mathrm{K}$ & $\begin{array}{l}\text { Monthly average soil temperature from } 0 \text { - to } 10-\mathrm{cm} \text { depth expressed every } 6 \mathrm{~h} \text { (e.g., all time } \\
\text { steps in January } 2002 \text { are the same, then ST000010 changes for February } 2002 \text {, etc). This } \\
\text { variable is relatively unimportant as it is used only to initialize the land surface model. }\end{array}$ \\
\hline ST040100 & $\mathrm{K}$ & Same as above, but for $10-40-\mathrm{cm}$ depth. \\
\hline ST040100 & $\mathrm{K}$ & Same as above, but for $40-100-\mathrm{cm}$ depth. \\
\hline ST100200 & $\mathrm{K}$ & Same as above, but for $100-200-\mathrm{cm}$ depth. \\
\hline SM000010 & Fraction & $\begin{array}{l}\text { Monthly average soil water fraction from } 0 \text { - to } 10-\mathrm{cm} \text { depth expressed every six hours (e.g., } \\
\text { all time steps in January } 2002 \text { are the same, then SM000010 changes for February } 2002 \text {, } \\
\text { etc). This variable is relatively unimportant as it is used only to initialize the land } \\
\text { surface model. }\end{array}$ \\
\hline SM010040 & Fraction & Same as above, but for $10-40-\mathrm{cm}$ depth. \\
\hline SM040100 & Fraction & Same as above, but for $40-100-\mathrm{cm}$ depth. \\
\hline SM100200 & Fraction & Same as above, but for $100-200-\mathrm{cm}$ depth. \\
\hline PMSL & $\mathrm{Pa}$ & $\begin{array}{l}\text { 6-hourly mean sea level pressure from CESM. PMSL is diagnosed from surface geopotential } \\
\text { and pressure and the lowest model level temperature and pressure from CESM using the } \\
\text { ECMWF methodology. }\end{array}$ \\
\hline PSFC & $\mathrm{Pa}$ & 6-hourly surface pressure from CESM. \\
\hline UU & $\mathrm{m} \mathrm{s}^{-1}$ & $\begin{array}{l}\text { 6-hourly zonal wind speed from CESM. The } 10-\mathrm{m} \text { winds are diagnosed from the lowest } \\
\text { CESM model level winds using a power law that assumes the winds diminish to zero at the } \\
\text { surface. }\end{array}$ \\
\hline VV & $\mathrm{m} \mathrm{s}^{-1}$ & $\begin{array}{l}\text { 6-hourly meridional wind speed from CESM. The } 10 \text {-m winds are diagnosed from the lowest } \\
\text { CESM model level winds using a power law that assumes the winds diminish to zero at the } \\
\text { surface. }\end{array}$ \\
\hline TT & $\mathrm{K}$ & $\begin{array}{l}\text { 6-hourly temperature fields from CESM. The 2-m temperature is diagnosed from the two } \\
\text { lowest CESM model levels by linear extrapolation. }\end{array}$ \\
\hline RH & $\%$ & $\begin{array}{l}\text { 6-hourly relative humidity fields from CESM. The } 2-\mathrm{m} \text { relative humidity is assumed to be } \\
\text { the same as the RH on the lowest CESM model level. }\end{array}$ \\
\hline GHT & $\mathrm{m}$ & 6-hourly geopotential height from CESM. \\
\hline
\end{tabular}

the continental area. The precipitation intensity increases in the Arabian Gulf and the southern Zagros Mountains in the wet season, and decreases in the margin of the tropics. In the dry season, the change in precipitation intensity is geographically variable, indicating strong impacts by individual precipitation events.

3) The wet index decreases over most areas of the Arabian Gulf region in a warmer climate except for the Arabian Gulf itself. The increases in both the precipitation intensity and wet index over the Arabian Gulf result in an increase in the precipitation amount, while over land the decrease in wet index compensates for the precipitation intensity increase, resulting in decrease in the precipitation. In most areas of the Arabian Gulf region, the maximum dry spell increases, especially near the margins of the tropical area, with an average value of 25 days $(10.67 \%)$.

4) Both the thermodynamic and dynamic impacts contribute to the changes in precipitation. Over the ocean, increases in the MLCAPE and MLCIN lead to more precipitation, while over the land arid conditions suppress convection. Thus, there is little increase in the convective events and the mean MLCAPE remains similar. In addition, the lowlevel cross-mountain wind speed decreases, especially in wet seasons, which results in a decrease in the precipitation amount in the mountainous areas.

The simulations presented in this study provide a unique dataset to study the regional climate of the Arabian Gulf region. Future studies include a better understanding of the changes in precipitation efficiency, the extreme 
events, the hydrological cycle, and the relative contributions of thermodynamic impacts and dynamic impacts on the changes in the precipitation climatology.

Acknowledgments. This work is supported by the National Center of Meteorology, Abu Dhabi, UAE, under the UAE Research Program for Rain Enhancement Science, Jiangsu Provincial Basic Research Programme (Natural Science Fund BK20190777), Science and Technology Innovation Project for Overseas Students in Nanjing (R2019LZ08), Capacity Building Project of Weather Modification in Northwest China (ZQCR18211, ZQC-R19081, RYSY201902). The lead author was funded by the Startup Foundation for Introducing Talent of NUIST (2018r094). We would like to acknowledge the high-performance computing support from Cheyenne supercomputer provided by NCAR's Computational and Information Systems Laboratory, sponsored by the National Science Foundation. We appreciate the editor and anonymous reviewers for the constructive comments and suggestions.

\section{APPENDIX}

\section{List of the Bias-Corrected Variables in the Intermediate Files}

Table A1 provides descriptions of the bias-corrected variables in the 6-hourly intermediate files to drive the BCD WRF simulations.

\section{REFERENCES}

Allan, R. P., and B. J. Soden, 2008: Atmospheric warming and the amplification of precipitation extremes. Science, 321, 14811484, https://doi.org/10.1126/science.1160787.

Al-Rashed, M. F., and M. M. Sherif, 2000: Water resources in the GCC countries: An overview. Water Resour. Manage., 14, 5975, https://doi.org/10.1023/A:1008127027743.

Ban, N., J. Schmidli, and C. Schär, 2014: Evaluation of the convection-resolving regional climate modeling approach in decade-long simulations. J. Geophys. Res. Atmos., 119, 78897907, https://doi.org/10.1002/2014JD021478.

Bender, M. A., T. R. Knutson, R. E. Tuleya, J. J. Sirutis, G. A. Vecchi, S. T. Garner, and I. M. Held, 2010: Modeled impact of anthropogenic warming on the frequency of intense Atlantic hurricanes. Science, 327, 454-458, https://doi.org/10.1126/science.1180568.

Bruyère, C. L., J. M. Done, G. J. Holland, and S. Fredrick, 2014: Bias corrections of global models for regional climate simulations of high-impact weather. Climate Dyn., 43, 1847-1856, https://doi.org/10.1007/s00382-013-2011-6.

—, A. J. Monaghan, D. F. Steinhoff, and D. Yates, 2015: Biascorrected CMIP5 CESM data in WRF/MPAS intermediate file format. NCAR/TN-515+STR, https://doi.org/10.5065/D6445JJ7.

Chenoweth, J., P. Hadjinicolaou, A. Bruggeman, J. Lelieveld, Z. Levin, M. A. Lange, E. Xoplaki, and M. Hadjikakou, 2011:
Impact of climate change on the water resources of the eastern Mediterranean and Middle East region: Modeled 21st century changes and implications. Water Resour. Res., 47, W06506, https://doi.org/10.1029/2010WR010269.

Chou, C., J. D. Neelin, C. A. Chen, and J. Y. Tu, 2009: Evaluating the "rich-get-richer" mechanism in tropical precipitation change under global warming. J. Climate, 22, 1982-2005, https://doi.org/10.1175/2008JCLI2471.1.

Colette, A., R. Vautard, and M. Vrac, 2012: Regional climate downscaling with prior statistical correction of the global climate forcing. Geophys. Res. Lett., 39, L13707, https://doi.org/ 10.1029/2012GL052258.

Colle, B. A., 2004: Sensitivity of orographic precipitation to changing ambient conditions and terrain geometries: An idealized modeling perspective. J. Atmos. Sci., 61, 588-606, https://doi.org/ 10.1175/1520-0469(2004)061<0588:SOOPTC $>2.0$.CO;2.

Coppola, E., and Coauthors, 2018: A first-of-its-kind multi-model convection permitting ensemble for investigating convective phenomena over Europe and the Mediterranean. Climate Dyn., 55, 3-34, https://doi.org/10.1007/S00382-018-4521-8.

Dee, D. P., and Coauthors, 2011: The ERA-Interim reanalysis: Configuration and performance of the data assimilation system. Quart. J. Roy. Meteor. Soc., 137, 553-597, https://doi.org/ 10.1002/qj.828.

Done, J. M., G. J. Holland, C. L. Bruyère, L. R. Leung, and A. Suzuki-Parker, 2015: Modeling high-impact weather and climate: Lessons from a tropical cyclone perspective. Climatic Change, 129, 381-395, https://doi.org/10.1007/ s10584-013-0954-6.

Hausfather, Z., and G. P. Peters, 2020: Emissions-The 'business as usual' story is misleading. Nature, 577, 618-620, https:// doi.org/10.1038/d41586-020-00177-3.

Held, I. M., and B. J. Soden, 2006: Robust responses of the hydrological cycle to global warming. J. Climate, 19, 5686-5699, https://doi.org/10.1175/JCLI3990.1.

Hemming, D., C. Buontempo, E. Burke, M. Collins, and N. Kaye, 2010: How uncertain are climate model projections of water availability indicators across the Middle East? Philos. Trans. Roy. Soc., A368, 5117-5135, https://doi.org/10.1098/rsta.2010.0174.

Huffman, G. J., and Coauthors, 2007: The TRMM multisatellite precipitation analysis (TMPA): Quasi-global, multiyear, combined-sensor precipitation estimates at fine scales. J. Hydrometeor., 8, 38-55, https://doi.org/10.1175/JHM560.1.

Iguchi, T., T. Kozu, R. Meneghini, J. Awaka, and K. I. Okamoto, 2000: Rain-profiling algorithm for the TRMM precipitation radar. J. Appl. Meteor., 39, 2038-2052, https://doi.org/10.1175/ 1520-0450(2001)040<2038:RPAFTT >2.0.CO;2.

Ikeda, K., and Coauthors, 2010: Simulation of seasonal snowfall over Colorado. Atmos. Res., 97, 462-477, https://doi.org/ 10.1016/j.atmosres.2010.04.010.

IPCC, 2013: Climate Change 2013: The Physical Science Basis. T. F. Stocker et al., Eds., Cambridge University Press, 1535 pp.

Jing, X., B. Geerts, Y. Wang, and C. Liu, 2017: Evaluating seasonal orographic precipitation in the interior western United States using gauge data, gridded precipitation estimates, and a regional climate simulation. J. Hydrometeor., 18, 2541-2558, https://doi.org/10.1175/JHM-D-17-0056.1.

_ $-\ldots, \ldots$, and ——, 2018: Ambient factors controlling the wintertime precipitation distribution across mountain ranges in the interior western United States. Part I: Insights from regional climate simulations. J. Appl. Meteor. Climatol., 57,1931-1954, https://doi.org/10.1175/ JAMC-D-17-0291.1. 
,,--- , and -2019 : Ambient factors controlling the wintertime precipitation distribution across mountain ranges in the interior western United States. Part II: Changes in orographic precipitation distribution in a pseudo global warming climate. J. Appl. Meteor. Climatol., 58, 695-715, https://doi.org/10.1175/JAMC-D-18-0173.1.

Khain, A. P., and Coauthors, 2015: Representation of microphysical processes in cloud-resolving models: Spectral (bin) microphysics versus bulk parameterization. Rev. Geophys., 53, 247-322, https://doi.org/10.1002/2014RG000468.

Knutti, R., and J. Sedláček, 2013: Robustness and uncertainties in the new CMIP5 climate model projections. Nat. Climate Change, 3, 369-373, https://doi.org/10.1038/nclimate1716.

Kwarteng, A. Y., A. S. Dorvlo, and G. T. Vijaya Kumar, 2009: Analysis of a 27-year rainfall data (1977-2003) in the Sultanate of Oman. Int. J. Climatol., 29, 605-617, https://doi.org/10.1002/ joc.1727.

Laprise, R. R. D. E., and Coauthors, 2008: Challenging some tenets of regional climate modelling. Meteor. Atmos. Phys., 100, $3-$ 22, https://doi.org/10.1007/s00703-008-0292-9.

Levy, A. A., W. Ingram, M. Jenkinson, C. Huntingford, F. H. Lambert, and M. Allen, 2013: Can correcting feature location in simulated mean climate improve agreement on projected changes? Geophys. Res. Lett., 40, 354-358, https://doi.org/ 10.1002/2012GL053964.

Liu, C., and Coauthors, 2017: Continental-scale convectionpermitting modeling of the current and future climate of North America. Climate Dyn., 49, 71-95, https://doi.org/ 10.1007/s00382-016-3327-9.

Lorenz, C., and H. Kunstmann, 2012: The hydrological cycle in three state-of-the-art reanalyses: Intercomparison and performance analysis. J. Hydrometeor., 13, 1397-1420, https:// doi.org/10.1175/JHM-D-11-088.1.

Luce, C. H., J. T. Abatzoglou, and Z. A. Holden, 2013: The missing mountain water: Slower westerlies decrease orographic enhancement in the Pacific Northwest USA. Science, 342, 1360 1364, https://doi.org/10.1126/science.1242335.

Meehl, G. A., and Coauthors, 2007: Global climate projections. Climate Change 2007: The Physical Science Basis, S. Solomon et al., Eds., Cambridge University Press, 747-845.

Modarres, R., and A. Sarhadi, 2009: Rainfall trends analysis of Iran in the last half of the twentieth century. J. Geophys. Res., 114, D03101, https://doi.org/10.1029/2008JD010707.

Monaghan, A. J., D. F. Steinhoff, C. L. Bruyere, and D. Yates, 2014: NCAR CESM global bias-corrected CMIP5 output to support WRF/MPAS research. Research Data Archive at the National Center for Atmospheric Research, Computational and Information Systems Laboratory, accessed 2017, https:// doi.org/10.5065/D6DJ5CN4.

Moss, R. H., and Coauthors, 2010: The next generation of scenarios for climate change research and assessment. Nature, $\mathbf{4 6 3}, 747-$ 756, https://doi.org/10.1038/nature08823.

Musselman, K. N., M. P. Clark, C. Liu, K. Ikeda, and R. Rasmussen, 2017: Slower snowmelt in a warmer world. Nat. Climate Change, 7, 214-219, https://doi.org/10.1038/nclimate3225.

Nesbitt, S. W., and E. J. Zipser, 2003: The diurnal cycle of rainfall and convective intensity according to three years of TRMM measurements. J. Climate, 16, 1456-1475, https://doi.org/ 10.1175/1520-0442-16.10.1456.

Ouarda, T. B., C. Charron, K. N. Kumar, P. R. Marpu, H. Ghedira, A. Molini, and I. Khayal, 2014: Evolution of the rainfall regime in the United Arab Emirates. J. Hydrol., 514, 258-270, https://doi.org/10.1016/j.jhydrol.2014.04.032.
Palmer, T., and B. Stevens, 2019: The scientific challenge of understanding and estimating climate change. Proc. Natl. Acad. Sci. USA, 116, 24 390-24 395, https://doi.org/10.1073/pnas.1906691116.

Pendergrass, A. G., D. B. Coleman, C. Deser, F. Lehner, N. Rosenbloom, and I. R. Simpson, 2019: Nonlinear response of extreme precipitation to warming in CESM1. Geophys. Res. Lett., 46, 10 551-10 560, https://doi.org/10.1029/2019GL084826.

Pepin, N., and Coauthors, 2015: Elevation-dependent warming in mountain regions of the world. Nat. Climate Change, 5, 424430, https://doi.org/10.1038/nclimate2563.

Prein, A. F., and Coauthors, 2015: A review on regional convection-permitting climate modeling: Demonstrations, prospects, and challenges. Rev. Geophys., 53, 323-361, https://doi.org/10.1002/2014RG000475.

_, R. M. Rasmussen, K. Ikeda, C. Liu, M. P. Clark, and G. J. Holland, 2017: The future intensification of hourly precipitation extremes. Nat. Climate Change, 7, 48-52, https://doi.org/ 10.1038/nclimate3168.

Rasmussen, K. L., A. F. Prein, R. M. Rasmussen, K. Ikeda, and C. Liu, 2020: Changes in the convective population and thermodynamic environments in convection-permitting regional climate simulations over the United States. Climate Dyn., 55, 383-408, https://doi.org/10.1007/s00382-017-4000-7.

Rasmussen, R., and Coauthors, 2011: High-resolution coupled climate runoff simulations of seasonal snowfall over Colorado: A process study of current and warmer climate. J. Climate, 24, 3015-3048, https://doi.org/10.1175/2010JCLI3985.1.

_ - and Coauthors, 2014: Climate change impacts on the water balance of the Colorado headwaters: High-resolution regional climate model simulations. J. Hydrometeor., 15, 1091-1116, https://doi.org/10.1175/JHM-D-13-0118.1.

Reynolds, R. W., T. M. Smith, C. Liu, D. B. Chelton, K. S. Casey, and M. G. Schlax, 2007: Daily high-resolution-blended analyses for sea surface temperature. J. Climate, 20, 5473-5496, https://doi.org/10.1175/2007JCLI1824.1.

Riahi, K., and Coauthors, 2011: RCP 8.5-A scenario of comparatively high greenhouse gas emissions. Climatic Change, 109, 33-57, https://doi.org/10.1007/s10584-011-0149-y.

Schmidli, J., and C. Frei, 2005: Trends of heavy precipitation and wet and dry spells in Switzerland during the 20th century. Int. J. Climatol., 25, 753-771, https://doi.org/10.1002/joc.1179.

Schumacher, C., and R. A. Houze Jr., 2000: Comparison of radar data from the TRMM satellite and Kwajalein oceanic validation site. J. Appl. Meteor., 39, 2151-2164, https://doi.org/ 10.1175/1520-0450(2001)040<2151:CORDFT > 2.0.CO;2.

_ and - 2003: Stratiform rain in the tropics as seen by the TRMM precipitation radar. J. Climate, 16, 1739-1756, https:// doi.org/10.1175/1520-0442(2003)016<1739:SRITTA >2.0.CO;2.

Serra, C., M. D. Martínez, X. Lana, and A. Burgueño, 2014: European dry spell regimes (1951-2000): Clustering process and time trends. Atmos. Res., 144, 151-174, https://doi.org/ 10.1016/j.atmosres.2013.05.022.

Simmons, A., S. Uppala, D. Dee, and S. Kobayashi, 2006: ERA-Interim: New ECMWF reanalysis products from 1989 onwards. ECMWF Newsletter, No. 110, 25-35, https:// www.ecmwf.int/sites/default/files/elibrary/2006/14615-newsletterno110-winter-200607.pdf.

Smith, R. B., and I. Barstad, 2004: A linear theory of orographic precipitation. J. Atmos. Sci., 61, 1377-1391, https://doi.org/ 10.1175/1520-0469(2004)061<1377:ALTOOP>2.0.CO;2.

Taylor, K. E., R. J. Stouffer, and G. A. Meehl, 2012: An overview of CMIP5 and the experiment design. Bull. Amer. Meteor. Soc., 93, 485-498, https://doi.org/10.1175/BAMS-D-11-00094.1. 
Tripathi, O. P., and F. Dominguez, 2013: Effects of spatial resolution in the simulation of daily and subdaily precipitation in the southwestern US. J. Geophys. Res. Atmos., 118, 75917605, https://doi.org/10.1002/JGRD.50590.

Wang, Y., B. Geerts, and C. Liu, 2018: A 30-year convectionpermitting regional climate simulation over the interior western United States. Part I: Validation. Int. J. Climatol., 38, 3684-3704, https://doi.org/10.1002/joc.5527.

Wehbe, Y., D. Ghebreyesus, M. Temimi, A. Milewski, and A. Al Mandous, 2017: Assessment of the consistency among global precipitation products over the United Arab Emirates. J. Hydrol. Reg. Stud., 12, 122-135, https://doi.org/10.1016/ j.ejrh.2017.05.002.

, M. Temimi, D. T. Ghebreyesus, A. Milewski, H. Norouzi, and E. Ibrahim, 2018: Consistency of precipitation products over the Arabian Peninsula and interactions with soil moisture and water storage. Hydrol. Sci. J., 63, 408-425, https://doi.org/ 10.1080/02626667.2018.1431647.

- , and Coauthors, 2019: Analysis of an extreme weather event in a hyper-arid region using WRF-Hydro coupling, station, and satellite data. Nat. Hazards Earth Syst. Sci., 19, 1129-1149, https://doi.org/10.5194/nhess-19-1129-2019.

White, R. H., and R. Toumi, 2013: The limitations of bias correcting regional climate model inputs. Geophys. Res. Lett., 40 2907-2912, https://doi.org/10.1002/grl.50612.

Xu, Z., and Z. L. Yang, 2015: A new dynamical downscaling approach with GCM bias corrections and spectral nudging. J. Geophys. Res. Atmos., 120, 3063-3084, https://doi.org/ 10.1002/2014JD022958.
Yang, J., Z. Wang, and A. Heymsfield, 2018: On the freezing time of supercooled drops in developing convective clouds over tropical ocean. Atmos. Res., 211, 30-37, https://doi.org/10.1016/ j.atmosres.2018.04.023.

Yun, Y., and Coauthors, 2020: Convection-permitting regional climate simulation of warm-season precipitation over Eastern China. Climate Dyn., 54, 1469-1489, https://doi.org/10.1007/ s00382-019-05070-y.

Yuter, S. E., D. A. Stark, J. A. Crouch, M. Jordan Payne, and B. A. Colle, 2011: The impact of varying environmental conditions on the spatial and temporal patterns of orographic precipitation over the Pacific Northwest near Portland, Oregon. J. Hydrometeor., 12, 329-351, https:// doi.org/10.1175/2010JHM1239.1.

Zhang, C., Y. Wang, K. Hamilton, and A. Lauer, 2016a: Dynamical downscaling of the climate for the Hawaiian Islands. Part I: Present day. J. Climate, 29, 3027-3048, https://doi.org/10.1175/ JCLI-D-15-0432.1.

- and 2016b: Dynamical downscaling of the climate for the Hawaiian Islands. Part II: Projection for the late twenty-first century. J. Climate, 29, 8333-8354, https:// doi.org/10.1175/JCLI-D-16-0038.1.

Zittis, G., and Coauthors, 2017: The added value of convection permitting simulations of extreme precipitation events over the eastern Mediterranean. Atmos. Res., 191, 20-33, https:// doi.org/10.1016/j.atmosres.2017.03.002.

, and Coauthors, 2020: 21st century projections of extreme precipitation indicators for Cyprus. Atmosphere, 11, 343, https://doi.org/10.3390/atmos11040343. 